\title{
Disturbed Balance of Inhibitory Signaling Links Hearing Loss and Cognition
}

\author{
Marlies Knipper ${ }^{1 *}$, Wibke Singer ${ }^{1}$, Kerstin Schwabe ${ }^{2}$, Gisela E. Hagberg ${ }^{3,4}$, \\ Yiwen Li Hegner ${ }^{5,6}$, Lukas Rüttiger $^{1}$, Christoph Braun ${ }^{5,6}$ and Rüdiger Land ${ }^{7}$ \\ ${ }^{1}$ Department of Otolaryngology, Head and Neck Surgery, Tübingen Hearing Research Center (THRC), Molecular Physiology \\ of Hearing, University of Tübingen, Tübingen, Germany, ${ }^{2}$ Experimental Neurosurgery, Department of Neurosurgery, \\ Hannover Medical School, Hanover, Germany, ${ }^{3}$ Department of Biomedical Magnetic Resonance, University Hospital \\ Tübingen (UKT), Tübingen, Germany, ${ }^{4}$ High-Field Magnetic Resonance, Max Planck Institute for Biological Cybernetics, \\ Tübingen, Germany, ${ }^{5}$ MEG Center, University of Tübingen, Tübingen, Germany, ${ }^{6}$ Center of Neurology, Hertie-Institute \\ for Clinical Brain Research, University of Tübingen, Tübingen, Germany, ${ }^{7}$ Department of Experimental Otology, Institute \\ for Audioneurotechnology, Hannover Medical School, Hanover, Germany
}

\section{OPEN ACCESS}

Edited by:

R. Michael Burger,

Lehigh University, United States

Reviewed by:

Hiroshi Kuba,

Nagoya University, Japan Christian Keine,

University of Oldenburg, Germany Shaowen Bao,

University of Arizona, United States

${ }^{*}$ Correspondence: Marlies Knipper Marlies.Knipper@uni-tuebingen.de

Received: 29 September 2021

Accepted: 08 December 2021

Published: 06 January 2022

Citation:

Knipper M, Singer W, Schwabe K, Hagberg GE, Li Hegner Y, Rüttiger L, Braun C and Land R (2022) Disturbed Balance of Inhibitory Signaling Links Hearing Loss and Cognition.

Front. Neural Circuits 15:785603. doi: 10.3389/fncir.2021.785603
Neuronal hyperexcitability in the central auditory pathway linked to reduced inhibitory activity is associated with numerous forms of hearing loss, including noise damage, agedependent hearing loss, and deafness, as well as tinnitus or auditory processing deficits in autism spectrum disorder (ASD). In most cases, the reduced central inhibitory activity and the accompanying hyperexcitability are interpreted as an active compensatory response to the absence of synaptic activity, linked to increased central neural gain control (increased output activity relative to reduced input). We here suggest that hyperexcitability also could be related to an immaturity or impairment of tonic inhibitory strength that typically develops in an activity-dependent process in the ascending auditory pathway with auditory experience. In these cases, high-SR auditory nerve fibers, which are critical for the shortest latencies and lowest sound thresholds, may have either not matured (possibly in congenital deafness or autism) or are dysfunctional (possibly after sudden, stressful auditory trauma or age-dependent hearing loss linked with cognitive decline). Fast auditory processing deficits can occur despite maintained basal hearing. In that case, tonic inhibitory strength is reduced in ascending auditory nuclei, and fast inhibitory parvalbumin positive interneuron (PV-IN) dendrites are diminished in auditory and frontal brain regions. This leads to deficits in central neural gain control linked to hippocampal LTP/LTD deficiencies, cognitive deficits, and unbalanced extra-hypothalamic stress control. Under these conditions, a diminished inhibitory strength may weaken local neuronal coupling to homeostatic vascular responses required for the metabolic support of auditory adjustment processes. We emphasize the need to distinguish these two states of excitatory/inhibitory imbalance in hearing disorders: (i) Under conditions of preserved fast auditory processing and sustained tonic inhibitory strength, an excitatory/inhibitory imbalance following auditory deprivation can maintain precise hearing through a memory linked, transient disinhibition that leads to enhanced spiking fidelity (central neural gain介) (ii) Under conditions of critically diminished fast auditory processing and reduced tonic inhibitory strength, 
hyperexcitability can be part of an increased synchronization over a broader frequency range, linked to reduced spiking reliability (central neural gain $\Downarrow$ ). This latter stage mutually reinforces diminished metabolic support for auditory adjustment processes, increasing the risks for canonical dementia syndromes.

Keywords: inhibitory strength, fast auditory processing, PV interneurons, dementia, tinnitus, deafness, BDNF, hearing loss

\section{INTRODUCTION}

Hearing loss is a very common problem in the aging population of industrial societies. Globally, an estimated 1.57 billion people had hearing loss in 2019, accounting for one in five people (20.3\%) (Goman and Lin, 2016; Collaborators, 2021). The problem is even worse among the elderly; more than $25 \%$ of people over 60 suffer from hearing loss. Hearing loss not only impairs communication, social interaction, and quality of life, but has also been identified as a common risk factor for cognitive decline and Alzheimer's disease (Lin F. R. et al., 2011; Livingston et al., 2017; Montero-Odasso et al., 2020). However, at the moment there has been no confirmation of a direct link between hearing loss and cognitive decline, which is, instead, currently assumed to be based on differences in myelination (Lin H. W. et al., 2011), auditory cognitive dysfunctions, or neurodegenerative processes (Fortunato et al., 2016; Uchida et al., 2019; Johnson et al., 2021).

Here, we review how impaired auditory input can affect the excitatory/inhibitory balance within the central auditory system and suggest that hearing loss and cognitive decline may be linked through changes in the excitatory/inhibitory balance associated with the functional attenuation of distinct auditory fiber types. We further suggest that these changes in the excitatory/inhibitory balance may, in turn, influence neurovascular coupling, possibly further affecting cognitive function in aging.

In the following, we lay out this idea in more detail. First, we provide an overview of the development of inhibitory GABAergic circuits (see Section "Maturation of GABA-Responsive Neurons Prior to Hearing Onset"). Second, we describe the role that different auditory nerve-fiber types might play during development and in regulating the excitatory/inhibitory balance in the auditory system (see Section "Activity-Dependent Maturation of GABAergic Inhibitory Circuits After Hearing Onset: The Potential Role of Auditory Nerve Fibers"). We then discuss the role of fast auditory processing (see Box 1) may play for maintaining the excitatory/inhibitory balance and sustaining or improving stimulus resolution and discrimination above noise after, e.g., mild acoustic trauma or hearing deficits. We hypothesize that fast auditory processing is a prerequisite for an increased central neural gain process (see Box 2). Within this multi-level reinforcing framework, activity dependent brainderived neurotrophic factor (BDNF) and fast spiking PV-IN contribute to improving central auditory plasticity (see Section "Altered Excitation and Inhibition After Acoustic Trauma and Age-Related Hearing Loss Are Linked to Increased Central Neural Gain”). In other auditory impairments such as acute acoustic trauma, deafness, or tinnitus, hyperexcitability may be the result of reduced (tonic) inhibitory strength (see Box 3) following less-developed or impaired fast auditory processing and subsequent failure to recruit BDNF and PV-IN dependent increased central neural gain (see Section "Altered Excitation and Inhibition in Acute Acoustic Trauma, Deafness, and Tinnitus: Lost Fast Auditory Processing"). Further, we discuss how a decline in fast auditory nerve processing, when critically reducing tonic inhibitory strength in auditory nuclei, might be linked to cognitive deficits or autism (see Section "Altered Excitation and Inhibition Following Diminished Fast Auditory Processing Linked to 'Central' Hearing Loss"). Finally, we point to a possible role for inhibitory circuits in regulating neurovascular hemodynamic responses as a stress-sensitive process. Ultimately, under these conditions, deficits in central processing and auditory cognitive brain dysfunctions are expected. Sustained fast auditory processing and tonic inhibitory strength may be a key signature that bridge hearing and cognition (see Section "Coupling of Inhibitory/Excitatory Circuit Activation to Cerebral Blood Flow").

This article should not be understood to be all-encompassing, but a reference to the respective research interests of the authors, in order to increase awareness that the brain's hyperexcitability can have different origins, dependent on whether the inhibitory strength generated in microcircuits with auditory experience is maintained or not. We finally deliberately propose this view as a "general concept." In the best case, we hope to inspire an interdisciplinary effort to examine the suggested hypothesis in the context of various auditory diseases. Only then can personalized intervention strategies be successfully implemented to overcome such devastating disorders as dementia, to which auditory cognitive deficits may contribute.

\section{MATURATION OF BALANCED INHIBITORY/EXCITATORY CIRCUITS IN THE AUDITORY SYSTEM}

\section{Maturation of GABA-Responsive Neurons Prior to Hearing Onset}

A balance between excitation and inhibition is crucial for the precise encoding of complex sounds. In this context, it is important to consider that balanced excitatory/inhibitory neuronal activity develops only after hearing onset. Early in neonatal development, radially migrating neurons that originate in the ventricular zone of the pallium (cortex) give rise to glutamatergic pyramidal neurons, while a second population of tangentially migrating neurons, originating 
BOX 1 | Fast auditory processing.

We define fast auditory processing as the increase in auditory acuity that is linked to lowering of hearing thresholds, increased suprathreshold ABR waves I and IV, the shortening of first spike latencies, and widening of response dynamic range with auditory experience, all shown in DCN neurons (Eckert et al., 2021), IC neurons (Chumak et al., 2016), and auditory cortex neurons (de Villers-Sidani et al., 2007; Xu et al., 2010). Because high-SR auditory fibers determine the threshold of the auditory-nerve response measured by the compound action potential (CAP) (Bourien et al., 2014), and these highly active fibers enable the shortest-latency auditory responses whatever the characteristic frequency (Meddis, 2006; Heil et al., 2008), we hypothesize that fast (high-SR) auditory fibers are also responsible for lowering of thresholds and shortening of latency of cortical auditory responses with auditory experience (de Villers-Sidani et al., 2007). This improved auditory acuity occurs after hearing onset in rodents P11 (de Villers-Sidani et al., 2007) and in humans likely between the 27th embryonic week and 6th to 12th months after birth (Neville and Bavelier, 2002). Moreover, fast auditory processing is a likely prerequisite for precise temporal auditory coding, pure tone pitch perception, and frequency discrimination - all characteristics that are required for proper speech intelligibility (Oxenham, 2018) and experience-driven auditory attention (Addleman and Jiang, 2019).

BOX 2 | Increased central neural gain.

We define increased central neural gain as the identifiable network homeostasis that increases stimulus-evoked synchronous neural activity at the level of the inferior colliculus (IC) (ABR wave IV) relative to its input at the level of the auditory nerve (ABR wave I). Increased central neural gain can occur following, e.g., auditory deprivation (age, injury, and trauma) or sound enrichment. As a multi-level framework, central neural gain includes a positive auditory feedforward and positive fronto-striatal feedback cycle that require co-activation. Mechanistically increased central neural gain likely requires a reinforcement process, as it is also known from auditory perception or improved task performance [for a review see Irvine (2018a)]. During improved task performance, for example, PV-IN activity in frontal brain regions contributes to feedforward inhibition that narrows the window for temporal summation of EPSPs and action potential initiation in, e.g., principle neurons (Pouille and Scanziani, 2001). Through feedback inhibition, a sharpening of receptive fields and pattern separation is initiated (Leutgeb et al., 2007). During this process, stimulus resolution and discrimination above noise, as well as neuronal output activity, is facilitated in sensory systems through, e.g., cortical or prefrontal brain inhibitory neurons that specifically suppress the firing of other inhibitory neurons (Caraiscos et al., 2004; Cardin et al., 2009; Pi et al., 2013; Hu et al., 2014; Kim et al., 2016; Chen et al., 2017). This results in enhanced stimulus response reliability, decreased response variability, and increased signal-to-noise ratio (Sohal et al., 2009; Zhu et al., 2015; Espinoza et al., 2018).

in the ventricular zone of the subpallium (subcortical telencephalon), give rise to GABA-producing local-circuit neurons (Marin and Rubenstein, 2001). Tangentially migrating GABAergic neurons, which target either higher-level cortical regions or lower-level brain regions posterior to the midbrain, originate from different brain regions and are characterized by different paired-box (Pax) homeobox genes. The GABAergic interneurons that migrate from the subpallium to cortical regions are thought to express Pax6 (Maricich and Herrup, 1999; Marin and Rubenstein, 2001), while the GABAergic interneurons that migrate from ventricular zones to lower brain levels posterior to midbrain regions express Pax2 (Nornes et al., 1990; Maricich and Herrup, 1999; Rowitch et al., 1999; Fotaki et al., 2008).

In rodents, the radially migrating excitatory neurons, followed by the tangentially migrating GABAergic neurons, reach their final destinations around birth (Marin and Rubenstein, 2001; Markram et al., 2004; Li et al., 2018). At this stage, GABA at the GABA-responsive neurons still acts in excitatory fashion (Figure 1A), corresponding with a transient, initial hyperexcitability phase (Figure 1A, green arrows and crosses). In the cortex, this occurs after migration of GABAergic neurons to the cortical plate (Marin and Rubenstein, 2001).

The initial hyperexcitability is due to the high intracellular chloride concentration of GABA-responsive neurons, which when activated by GABA favors a chloride efflux and thereby a depolarization of the neuron (Ben-Ari et al., 1989; Marin and Rubenstein, 2001; Ben-Ari, 2002) (Figure 1A, inset red arrow $\mathrm{Cl}^{-}$). In the auditory pathway of rodents, it has been shown that, early in postnatal development and prior to hearing onset, a high intracellular chloride concentration $\left(\left[\mathrm{Cl}^{-}\right]_{i}\right)$ is maintained in most neurons, ensured by the sodium-potassium-chloride co-transporter type 1 (NKCC1) (Figure 1A, inset $\mathrm{NKCC} 1 \uparrow$ ). Hence, $\mathrm{Cl}^{-}$-mediated synaptic activities cause a depolarizing response (Balakrishnan et al., 2003; Cherubini et al., 2011; Friauf et al., 2011). Briefly, prior to hearing onset, around P5-P6 in rodents (Lohrke et al., 2005), or possibly driven by auditory experience, as shown after unilateral or bilateral cochlear ablation (Shibata et al., 2004), a switch of GABA-responsive neurons occurs and the effect of GABA changes from depolarizing to hyperpolarizing (Figure 1B). The switch from depolarizing to hyperpolarizing responses of GABA-responsive neurons is linked to an enhanced expression of the neuronal potassium chloride co-transporter type 2 (KCC2), which leads to a low concentration of intracellular chloride and, consequently, to a hyperpolarizing inhibitory postsynaptic potential upon GABA stimulation (Kandler and Gillespie, 2005) (Figure 1B, inset GABA KCC2 ). Accordingly, the levels of the KCC2 transporter in the brainstem and ascending associated hippocampal regions are expectedly low before hearing onset (Figure 1A, inset KCC $2 \Downarrow)$, and increase from the first postnatal week onward in a region-specific pattern (Figure 1B, inset KCC2介), as shown for the ascending auditory pathway (Lohrke et al., 2005) and other brain regions (Kandler and Friauf, 1995; Rivera et al., 1999; Friauf et al., 2011; Hirtz et al., 2011; Watanabe and Fukuda, 2015). This is the time when an upregulation of activity-dependent $B d n f$ transcripts is observed in cochlear spiral ganglion neurons (SGN) and at lower auditory brain levels (Singer et al., 2014) (Figure 1B, BDNF介). BDNF is suggested to modulate GABAergic synapses by postsynaptic regulation of chloride transport (Wardle and Poo, 2003). Since BDNF drives the upregulation of KCC2 expression (Ben-Ari et al., 2012) and both BDNF (Aid et al., 2007) and KCC2 (Fiumelli et al., 2005; Wake et al., 2007) are controlled by neuronal activity (Awad et al., 2018), the switch from depolarizing to hyperpolarizing responses of projecting neurons may start in the ascending auditory pathway and associated limbic frontal 
BOX 3 | Tonic inhibitory strength.

We define tonic inhibitory strength as a sustained form of microcircuit network suppression. In the case of loss of inhibitory strength, spontaneous firing rate would increase without increasing a stimulus-evoked spike output. In the cerebellar cortex, such a phenomenon was described after a blockade of tonic inhibition in granule cells (Duguid et al., 2012). It is currently assumed that tonic inhibition suppresses spontaneous activity through a reduction of the neuronal input resistance and membrane time constants, thereby improving stimulus discrimination above noise (Caraiscos et al., 2004). The ability of tonic inhibition to change conductance in many neurons is assumed to require perisynaptic and extrasynaptic $\delta$ subunit-containing $\mathrm{GABA}_{A}$ receptors, which are likely activated through fast-spiking, parvalbumin (PV)-expressing and soma-inhibiting interneurons (IN) (Ferando and Mody, 2015). When tonic PV-IN activity is functionally impaired, the rapid increase in bursting reduces the signal-to-noise ratio (Duguid et al., 2012). The pathological hyper-synchronization resembles electrical seizure activity (Rossignol et al., 2013; Fröhlich, 2016; Hsieh et al., 2017), and possibly enhances baseline spontaneous gamma power, reduces evoked gamma power (Mamashli et al., 2017), and can in this way also disturb the signal-to-noise ratio.

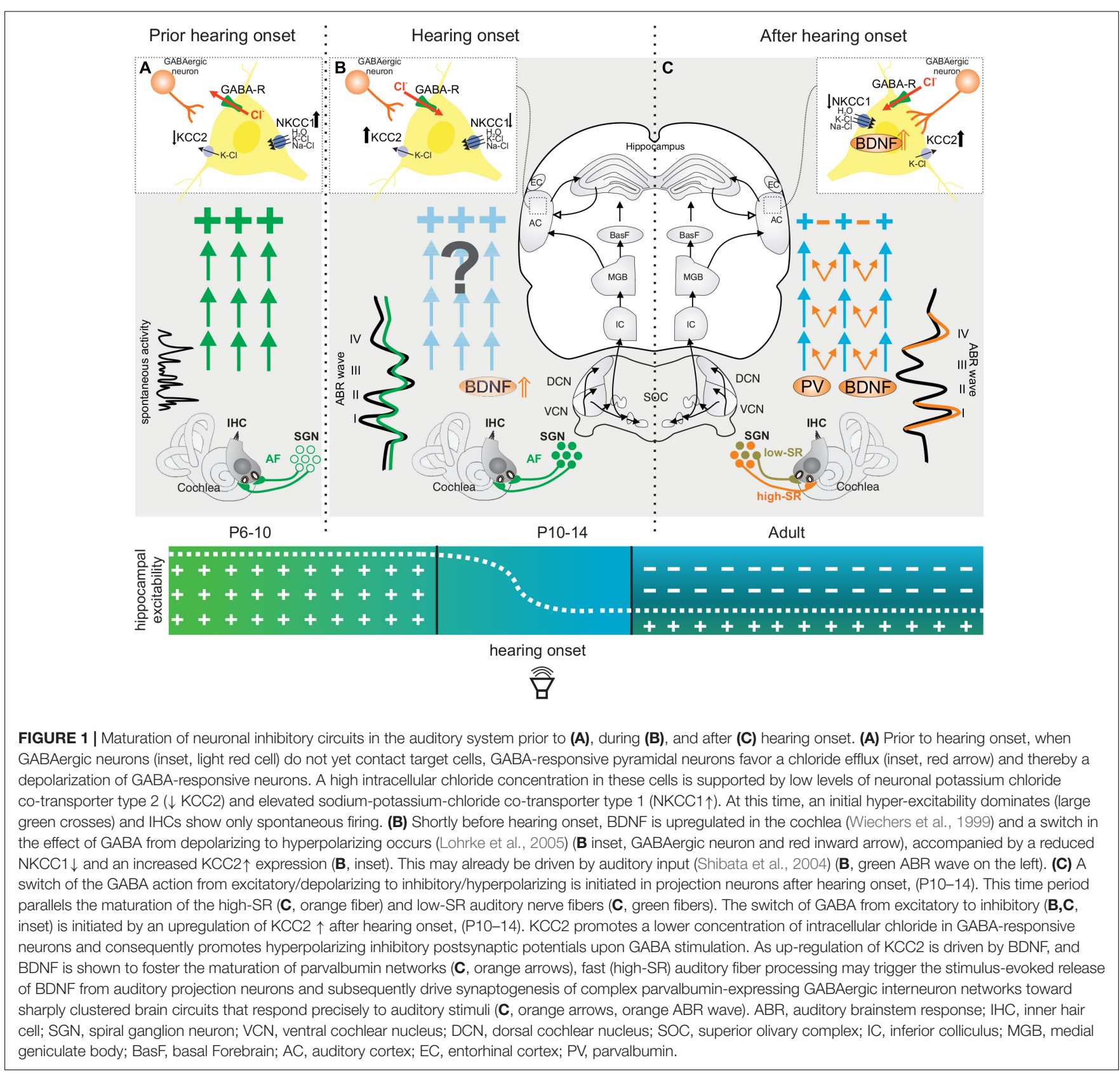

brain regions in response to an upregulation of activitydriven $B d n f$ transcripts. Activity-driven $B d n f$ transcripts are the result of independently transcribed non-coding exon IV and exon VI that, from a total of eight non-coding exons (I-VIII), are spliced to a common protein-encoding exon (IX) (Timmusk et al., 1993; Aid et al., 2007; Vaghi et al., 2014) 


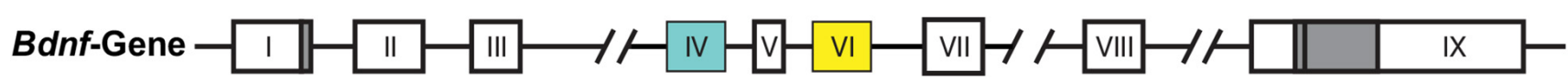

FIGURE 2 | Schematic drawing of the rodent Bdnf gene, which is composed of eight non-coding exons (I-VIII) that are individually transcribed and alternatively spliced to the protein-encoding exon IX. Bdnf exon IV and VI are directly or indirectly regulated by changes in neuronal activity. In BDNF-Live-Exon-Visualization (BLEV) mice (Matt et al., 2018; Singer et al., 2018b), BDNF exon IV and VI are individually labeled with either cyan (exon IV) or yellow (exon VI) fluorescence protein in regions of activity-dependent translation of BDNF. Modified after (Aid et al., 2007; Singer et al., 2018b).

(Figure 2). Both exon IV (Figure 2, cyan) and exon VI (Figure 2, yellow) comprise promoters directly or indirectly regulated by neuronal activity (Hong et al., 2008; Dieni et al., 2012; West et al., 2014; Chacon-Fernandez et al., 2016; Tuvikene et al., 2016).

In analogy to the visual system, the upregulation of BDNF in the cochlea and ascending pathway prior to hearing onset is suggested to occur in response to the influences of top-down hypothalamic corticotropin-releasing factor (CRF) (Knipper et al., 2015; Vetter, 2015). In response to these changes, spontaneous glutamate release from inner hair cells (IHCs), long predicted to play a crucial role in the maturation of central auditory circuits (Friauf and Lohmann, 1999; Kandler and Gillespie, 2005; Kandler et al., 2009; Hirtz et al., 2011), could activate $B d n f$ promoters in SGN to drive the depolarizingto-hyperpolarizing switch in a bottom-up direction within the ascending auditory circuits both prior to and following hearing onset (Figure 1B, BDNF介). This would prepare auditory microcircuits for the subsequently occurring experience-driven synaptogenesis of perisomatic GABAergic contacts with the ascending microcircuits (next section). Taking this into account, differences in the vulnerability of cochlear neurons related to altered cochlear BDNF (Meltser et al., 2014) or CRF levels (Graham and Vetter, 2011) may be reconsidered in future studies in the context of changes in cochlear BDNF or CRF might potentially affect GABAergic inhibitory strength in the auditory pathway.

In summary, prior to the first auditory experience and during hearing onset, an initial period of hyperexcitability exists, with excitatory activity dominating over inhibitory activity. Within this transient time period, GABA-responsive neurons have reached their target regions but still react with depolarizing responses, due to the low level of neuronal KCC2 and high $\left[\mathrm{Cl}^{-}\right]_{I}$ concentrations.

\section{Activity-Dependent Maturation of GABAergic Inhibitory Circuits After Hearing Onset: The Potential Role of Auditory Nerve Fibers}

When considering possible events that may be causally linked to inhibitory GABAergic circuit formation in the auditory system, it is interesting to focus on the differential maturation times of different types of auditory nerve fibers. These roughly 30,000 auditory nerve fibers in the mammalian inner ear receive signals from individual IHC via ribbon synapses (Spoendlin, 1969; Liberman, 1980; Nadol, 1988), and transmit the signals further to the subsequent structures of the central auditory pathway.
Auditory nerve fibers differ in their spontaneous firing rates (SR) and sound level thresholds and can be divided into at least two types. The low-SR, high-threshold auditory fibers, characterized by a low spontaneous firing rate of $<18$ spikes/s, comprise around $40 \%$ of all auditory nerve fibers, and the high-SR low threshold fibers, which have a high spontaneous firing rate $>18$ spikes/s, comprise the remaining 60\% (Sachs and Abbas, 1974; Liberman, 1982; Yates, 1991; Merchan-Perez and Liberman, 1996; Glowatzki and Fuchs, 2002; Grant et al., 2010). SGNs with different SRs form synapses at different modiolar-to-pillar positions along the basolateral surface of IHCs (Liberman, 1982).

The mechanism that leads to maturation and differentiation of the distinct SR characteristics of auditory nerve fiber types is still under debate. A recent study of Shrestha et al. (2018), identified characteristic patterns of genes in SGNs of mature mice (P25), that from their anatomical position across the IHCs were characteristic for SGN fates of high, middle, and low-SR auditory nerve fibers. They showed that prior to hearing onset, representative genes for the SGN fate of low-SR auditory nerve fibers are shaped out of pre-existing SGNs that have the SGN fate typical of high-SR auditory nerve fibers. This happens over time - between P3 and P8 - in an activity-dependent manner (Shrestha et al., 2018). This would mean that prior to hearing onset, the SGN fate of high-SR would precede that of low-SR fibers. In contrast, when auditory nerve activity was recorded at the time of hearing onset - in mice around P11-, their multivesicular excitatory postsynaptic currents (EPSCs) with lower amplitudes preceded and contrasted with monophasic EPSCs with sharp rise times and 10 times larger amplitudes that were recorded after hearing onset at P19-P21 (Grant et al., 2010). It was speculated that low EPSC amplitude distributions may represent fibers with low spontaneous rates (Figure 1C, light green fiber), 'as most synaptic events may be insufficiently large to activate APs.' In contrast, fibers with monophasic EPSCs and larger amplitudes may correspond to high-SR ANF (Figure 1C, orange fiber), as most excitatory postsynaptic potentials (EPSPs) may activate APs (Glowatzki and Fuchs, 2002; Grant et al., 2010). This suggested a substantial shift in the mode of transmitter release in IHCs, from preferential release of single vesicles in IHCs in immature animals during hearing onset, to preferential and coordinated release of seven to nine vesicles in IHCs from hearing animals (Grant et al., 2010).

In addition, medial efferents that form transient cholinergic synapses with IHCs during the first postnatal week (Glowatzki and Fuchs, 2000) may contribute to the different SR of auditory fibers or SGN fate (Knipper et al., 2015, review), as they alter the precision of spike timing of auditory fibers (Johnson et al., 2011, 2013). In analogy to the visual system, an altered spike timing 
precision may initiate, e.g., a hypothalamic top-down feedback signal to cochlear neurons, resulting in BDNF upregulation, here suggested to potentially influence the inhibitory strength of ANF (see Section "Maturation of GABA-Responsive Neurons Prior to Hearing Onset"). This may be analogous to the BDNF- and dopamine-induced improvement of retinal acuity through receptive-field re-organization of retinal ganglion cells (RGCs) (Sinclair et al., 2004; Witkovsky, 2004; Landi et al., 2009). Moreover, lateral dopaminergic feedback to auditory nerve fibers may influence high-SR rate characteristics, as shown by auditory nerve recording under dopaminergic receptor blockade (Ruel et al., 2006), as previously discussed in detail (Knipper et al., 2015). Here, a dopamine-induced modification of $\mathrm{GABA}_{A}$ receptor-mediated tonic inhibition may be considered (Crunelli and Di Giovanni, 2014).

Overall, it can be concluded that several events may contribute to the different physiological functions and firingrate characteristics of auditory nerve fibers in the mature auditory system (i) IHC-driven synaptic events that mature during hearing onset, (ii) differences in cochlear IHC output activity through differential maturation of efferent feedback to auditory fibers, as well as (iii) differences in the genetic fate of SGNs. After hearing onset, fast auditory processing (Box 1) matures with high-SR auditory nerve fiber responses that determine the threshold of compound action potentials of the auditory nerve (Bourien et al., 2014) and are responsible for the shortest latencies seen in auditory responses at any given characteristic frequency, suggesting that they determine the perceptual thresholds (Meddis, 2006; Heil et al., 2008). The process of high-SR auditory nerve fiber maturation is thus likely related to the increased ABR wave amplitudes and their shortened latencies after hearing onset $(\sim \mathrm{P} 11)$ in rodents (e.g., Song et al., 2006) as well as to the sharpening of cortical receptive fields observed in rodents between the 2 nd and 3 rd postnatal week (Lendvai et al., 2000; de Villers-Sidani et al., 2007; Takesian et al., 2018).

The sharpening of cortical receptive fields, i.e., narrower bandwidth responses, occurs for all sensory cortices, including the auditory cortex (Xu et al., 2010) as a result of the stimulusevoked release of BDNF from cortical pyramidal neurons (Itami et al., 2007; Hong et al., 2008; Xu et al., 2010; Lehmann et al., 2012; Griffen and Maffei, 2014; Kimura and Itami, 2019) (Figures 1B,C, BDNF $\Uparrow$ ). The released BDNF appears to drive the synaptogenesis of a complex network from peri-somatic and dendritic fast-spiking PV-INs that contact cortical pyramidal neurons (Hong et al., 2008; Xu et al., 2010; Lehmann et al., 2012) (Figure 1C, blue, orange arrows and inset). In accordance with this, between the 2 nd to 3 rd postnatal week, PV-IN staining levels increase in ascending auditory circuits and their cortical projections (Lohmann and Friauf, 1996), and inhibitory strength increases in microcircuits, as also observed in other sensory systems (Lohmann and Friauf, 1996; Itami et al., 2007; Xu et al., 2010; Lehmann et al., 2012; Kimura and Itami, 2019) (Figure 1C, inset perisomatic GABAergic contacts increase).

Important to mention here is that the overall process of maturation of fast auditory processing appears to be dispensable for basal hearing function. Thus, when BDNF was deleted in
GABAergic precursor neurons in the brainstem of mice under the Pax2 promoter, and despite normal hearing thresholds based on measuring outer hair cell function, supra-threshold auditory nerve (ABR wave I) amplitudes remained low and the late $A B R$ wave IV was delayed, indicating that fast auditory processing may have not matured properly (Zuccotti et al., 2012). As a result, profound deficits in precise auditory acuity occurred (Zuccotti et al., 2012; Chumak et al., 2016; Eckert et al., 2021), and was evident in the reduced dynamic range, elevated spontaneous firing rates (SFR), delayed first-spike latency, and reduced inhibitory strength in the dorsal cochlear nucleus and inferior colliculus (IC) (Chumak et al., 2016; Eckert et al., 2021). Under these conditions also, dendritic filopodia extensions of PVIN positive interneurons were few in the auditory cortex and hippocampus in comparison to wild-type animals, despite PVIN being normal in numbers (Eckert et al., 2021). This suggested that in rodents during the first postnatal weeks, the maturation of fast auditory processing (Figure 1C, high-SR in orange), the maturation of inhibitory strength in the ascending auditory pathway (Zuccotti et al., 2012; Chumak et al., 2016; Eckert et al., 2021) (Figure 1C, PV, orange arrows), and the stimulus-evoked release of BDNF from cortical pyramidal neurons (Figure 1C, inset, $\mathrm{BDNF} \Uparrow$ ) that drives the synaptogenesis of fast-spiking PVIN microcircuits (Xu et al., 2010) are events that depend on experiencing sound.

To obtain an idea when this critical time period of maturation of inhibitory strength occurs in auditory and associated circuits in humans, we have to consider that the fast inhibitory PV-IN activity regulates not only higher cortical microcircuit functions (Griffen and Maffei, 2014; Kimura and Itami, 2019), but also feedforward and feedback inhibition (Hu et al., 2014, 2018) and its functional correlates, i.e., the gamma- and beta frequency oscillations (Cardin et al., 2009; Sohal et al., 2009; Gill and Grace, 2014; Chen et al., 2017). In children, increased gamma oscillations, associated with feedforward inhibition, occur at the age of less than 6 months, and are followed by increased beta oscillations, reflecting feedback inhibition (Sowell et al., 2001; Ortiz-Mantilla et al., 2016). At the same time, the latencies of the sound-induced auditory brainstem response (ABR) become shorter (Neville and Bavelier, 2002; Sharma et al., 2016). In parallel, functional brain connectivity increases from the 6th month of age onwards, when the neural activity becomes more clustered and specific for sensory modalities (Sowell et al., 2001; Neville and Bavelier, 2002; Ortiz-Mantilla et al., 2016) (Figure 1B, blue arrow). The clustering of sensory modalities, in turn, is accompanied by an enhanced comprehension of speech in noise (Obleser et al., 2007; Youssofzadeh et al., 2018), all progressing with a gradually improved capacity for auditory discrimination and temporal discrimination (Sowell et al., 2001; Fox et al., 2012; Miller and Buschman, 2013; Ankmnal Veeranna et al., 2019).

We thus conclude that auditory experience-dependent maturation processes of high-SR auditory nerve fibers in the auditory system are critical for the maturation of fast auditory processing, including the formation of activitydriven, fast inhibitory PV-IN microcircuits. Only then is the neuronal network implemented for a fine-grained resolution 
of sound discrimination, temporally precise hearing, and fast discrimination of novel auditory information (Figures 1B,C).

\section{ALTERED EXCITATION AND INHIBITION AFTER ACOUSTIC TRAUMA AND AGE-RELATED HEARING LOSS ARE LINKED TO INCREASED CENTRAL NEURAL GAIN}

Numerous studies have indicated that acoustic trauma and agedependent hearing loss are linked to reduced inhibition and enhanced excitation in ascending auditory circuits (Gerken, 1996; Milbrandt et al., 2000; Caspary et al., 2008; Wang et al., 2012; Ouda et al., 2015; Recanzone, 2018). Since low-SR auditory nerve fibers are vulnerable to noise damage and aging (Figure 3, lowSR in light green) (Heinz and Young, 2004; Heinz et al., 2005; Ruel et al., 2008; Kujawa and Liberman, 2009; Wang et al., 2012; Furman et al., 2013; Sergeyenko et al., 2013; Plack et al., 2014; Wu et al., 2019), deficits in this auditory nerve fiber type have been linked with temporal auditory discrimination deficits that follow acoustic trauma and age-related hearing loss in animals (Kujawa and Liberman, 2009; Plack et al., 2014; Wu et al., 2019) and humans (Liberman and Kujawa, 2017; Wu et al., 2019). Temporal auditory discimination deficits include those in spike timing and the synchronization of neural auditory responses that were shown to be required for following amplitude-modulated stimuli (Kuwada et al., 2002; Johnson et al., 2021). Auditory steady state responses are also an indicator for the proper processing of amplitude-modulated acoustic stimuli in subcortical areas and in the frontocentral cortex (Engelien et al., 2000). Previous studies indicated that during aging or after acoustic trauma, auditory response latencies can be shortened, and temporal coding, as measured through auditory steady state responses, enhanced (Möhrle et al., 2016; Eckert et al., 2021) when ABR wave IV is disproportionally elevated in response to a reduced $A B R$ wave I (Figure 3, ABR wave in blue), a feature suggested to be linked to increased central neural gain (Box 2) (Figure 3, enhanced blue crosses).

In addition to low-SR auditory fiber processing sounds (Bharadwaj et al., 2015; Liberman, 2017), sustained fast (high-SR) auditory processing, is thus also critical for central neural gain and temporal auditory coding (Möhrle et al., 2017; Eckert et al., 2021). In line with this, computational models suggested that in response to deprived auditory input, the generation of sufficiently high discharge rates for centrally compensating homeostatic network changes may only work under conditions of preserved high-SR auditory nerve fibers (Schaette and Kempter, 2009). Diminished auditory input after acoustic trauma (Figure 3, crossed low-SR fibers contacting IHCs) has long been reported to possibly lead to a homeostatic network change and to an upregulation of neuronal responsiveness in central circuits (Salvi et al., 2000) (Figure 3, enhanced blue crosses). This homeostatic network change can be accompanied by a disproportional elevation of discharge rates as seen in the amplitude ratio of late $A B R$ wave IV to early $A B R$ wave I (Figure 3, $A B R$ wave).
Enhanced output relative to input in auditory neurons after acoustic trauma is suggested to be the result of disinhibition of neurons in the ventral or dorsal cochlear nucleus (Brigande and Heller, 2009; Cai S. et al., 2009; Schaette and Kempter, 2009; Schaette and McAlpine, 2011; Gu et al., 2012) or neurons of the IC (Gu et al., 2012; Heeringa and van Dijk, 2014). The subsequent hyperexcitability (Figure 3, high-SR in orange) spreads to the auditory cortex (Lu et al., 2011). The increased output of, e.g., $\mathrm{CN}$ neurons has been linked to steeper rate-level functions and a smaller dynamic range (Cai R. et al., 2009). As described for improved auditory perception, the process of accentuation of auditory stimuli that leads to central neural gain may require the co-activation of the basal forebrain to amplify stimulusinduced responses at subcortical and cortical levels (Figure 3, BasF blue downward arrow and cross) (Kilgard et al., 2002; Bajo et al., 2014; Kraus and White-Schwoch, 2015; Irvine, 2018a). Also, the activation of the inferior frontal gyrus (IFG), as part of the prefrontal cortex (PFC) (Figure 3, IFG), is crucial to retaining temporal and spatial associations of auditory events during auditory perception (Schonwiesner et al., 2007; Malmierca et al., 2014; Jafarpour et al., 2019). In general, the activation of PFC brain regions during perception is crucial to memorizing behaviorally relevant signals and increasing synaptic strength (Kraus and White-Schwoch, 2015; Weinberger, 2015; Irvine, 2018b). Particular and distinct medial (mPFC) and dorsolateral PFC (dlPFC) regions display crucial functions for basal inhibition of the hypothalamic-pituitary-adrenal (HPA) axis reactivity during central adjustment processes [review in Sullivan and Gratton (2002); Meltser and Canlon (2011), Canlon et al. (2013); de Kloet et al. (2014)de Kloet et al. (2019); Irvine (2018a), and Viho et al. (2019)]. Finally, in the auditory cortex, central neural gain control has been linked to feedforward inhibition, driven by the PV-IN, that spreads from the thalamus to the auditory cortex, eliciting amplified sound responses (Rabinowitz et al., 2012; Ji et al., 2016; Lohse et al., 2020; Pennington and David, 2020). The crucial role of PV-IN activation for central neural gain is emphasized through PV-IN potentiating drugs, which in the auditory cortex can trigger an enhanced signal-to-noise ratio (Deng et al., 2020). Optogenetic activation of PV-neurons, moreover, reduced spiking in the auditory cortex in general while enhancing functional connectivity (Hamilton et al., 2013). In the somatosensory and visual systems, an activation of PV-IN neurons is linked to enhanced stimulus-induced performance (Kim et al., 2016; Chen et al., 2017) that leads to enhanced response reliability, decreased signal variability, and improved reliability of signal information processing through an improved signal-to-noise ratio (Cardin et al., 2009; Sohal et al., 2009; Zhu et al., 2015) (Figure 3, Cortical resolution $\Uparrow$ ).

Evidence that the activity-dependent BDNF recruitment may be part of this homeostatic central neural gain process (Figure 3, BDNF $\Uparrow$ ) came from experiments using BDNFLive-Exon-Visualization (BLEV) reporter mice, generated to monitor the activity-dependent usage of BDNF from exon IV and exon VI. In these mice, stimulus-induced changes in $B d n f$ transcripts can be seen in nerve endings, glia cells, and capillaries (Matt et al., 2018; Singer et al., 2018b). This is in line with observations of activity-driven $B d n f$ transcripts shown for 


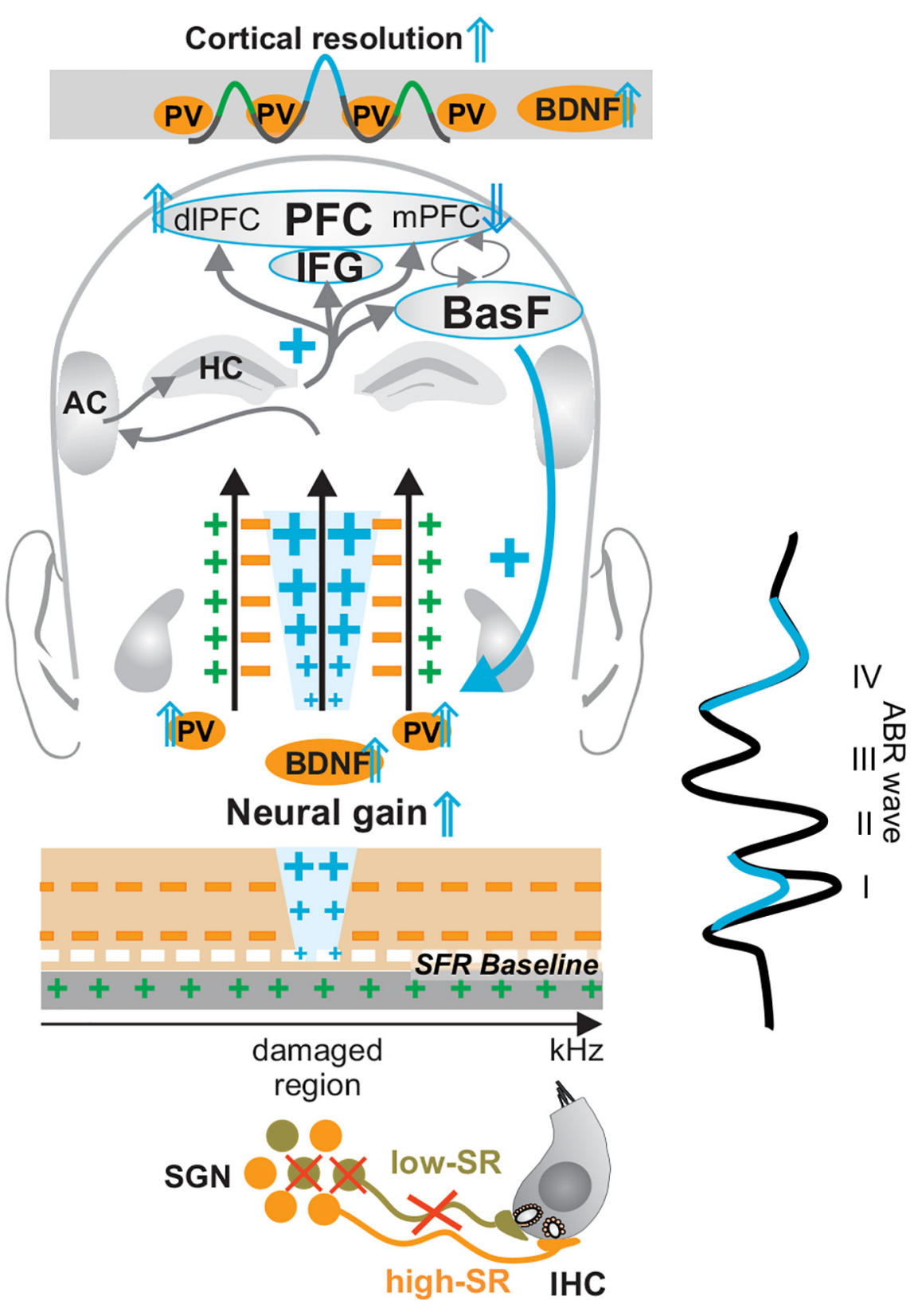

FIGURE 3 | Central neural gain mechanism following mild acoustic trauma and aging. When the numbers of low-SR auditory fibers (in light green) decline during aging or following auditory damage, a significantly enhanced output of central circuits (central compensation and enhanced blue crosses) may critically depend on the maintained activity of high-SR auditory fibers (in orange), to assure the generation of high discharge rates and central compensation of deprived auditory input (ABR wave in blue). During this process of central neural gain (blue crosses), a BDNF- and memory-dependent amplification process requires the activation of hippocampal circuits (upper blue cross), the activation of the basal forebrain (BasF), the balancing activation of dorsolateral, medial prefrontal cortex (dIPFC and mPFC) and specific PFC regions, such as the inferior frontal gyrus (IFG), to enhance auditory signals above noise levels (feedback mechanism, blue downward arrow and cross on the right side). Modified after Knipper et al. (2020). IHC, inner hair cell; SGN, spiral ganglion neuron; SFR, spontaneous firing rate; HC, hippocampus; IFG, inferior frontal gyrus; BasF, basal Forebrain; PFC, prefrontal cortex; dIPFC, dorsolateral PFC; mPFC, medial PFC; AC, auditory cortex; PV, parvalbumin.

platelets (Chacon-Fernandez et al., 2016), capillary endothelial cells (Donovan et al., 2000), microglia, and astrocytes (Ferrini and De Koninck, 2013; Parkhurst et al., 2013). In BLEV mice 2 weeks after $80 \mathrm{~dB}$ SPL exposure, both wave I (Figure 4A) and wave IV (Matt et al., 2018) were elevated (=sustained elevation), whereas through mild acoustic trauma using $100 \mathrm{~dB}$ SPL exposure, wave
I (Figure 4A) was reduced and wave IV (Matt et al., 2018) was unchanged (=centrally compensated) [see differences in Figures 4A,B, in control, 80 and 100 dB, (Matt et al., 2018)]. This was linked to elevated $B d n f$ exon IV/VI transcript levels both in the brainstem (Matt et al., 2018) and hippocampal CA3 region (Matt et al., 2018) (Figure 4C, yellow and cyan), 
A

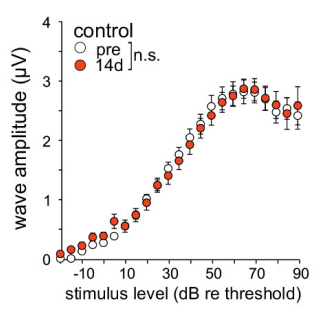

B

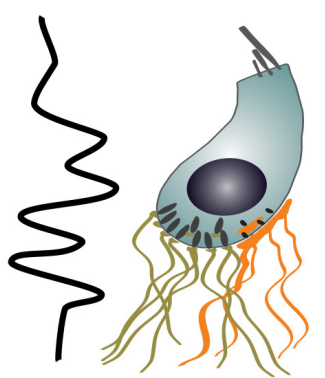

C

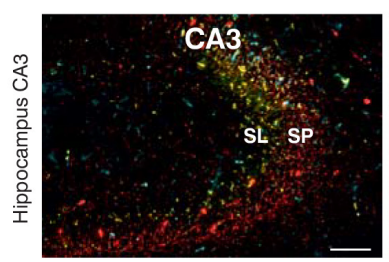

D

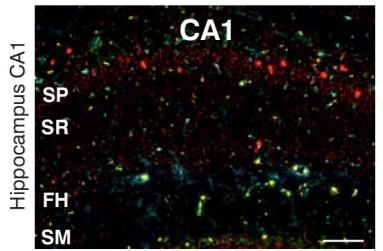

E

Control

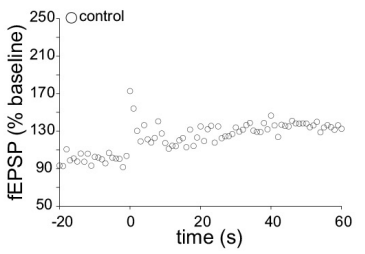

ABR wave I amplitude
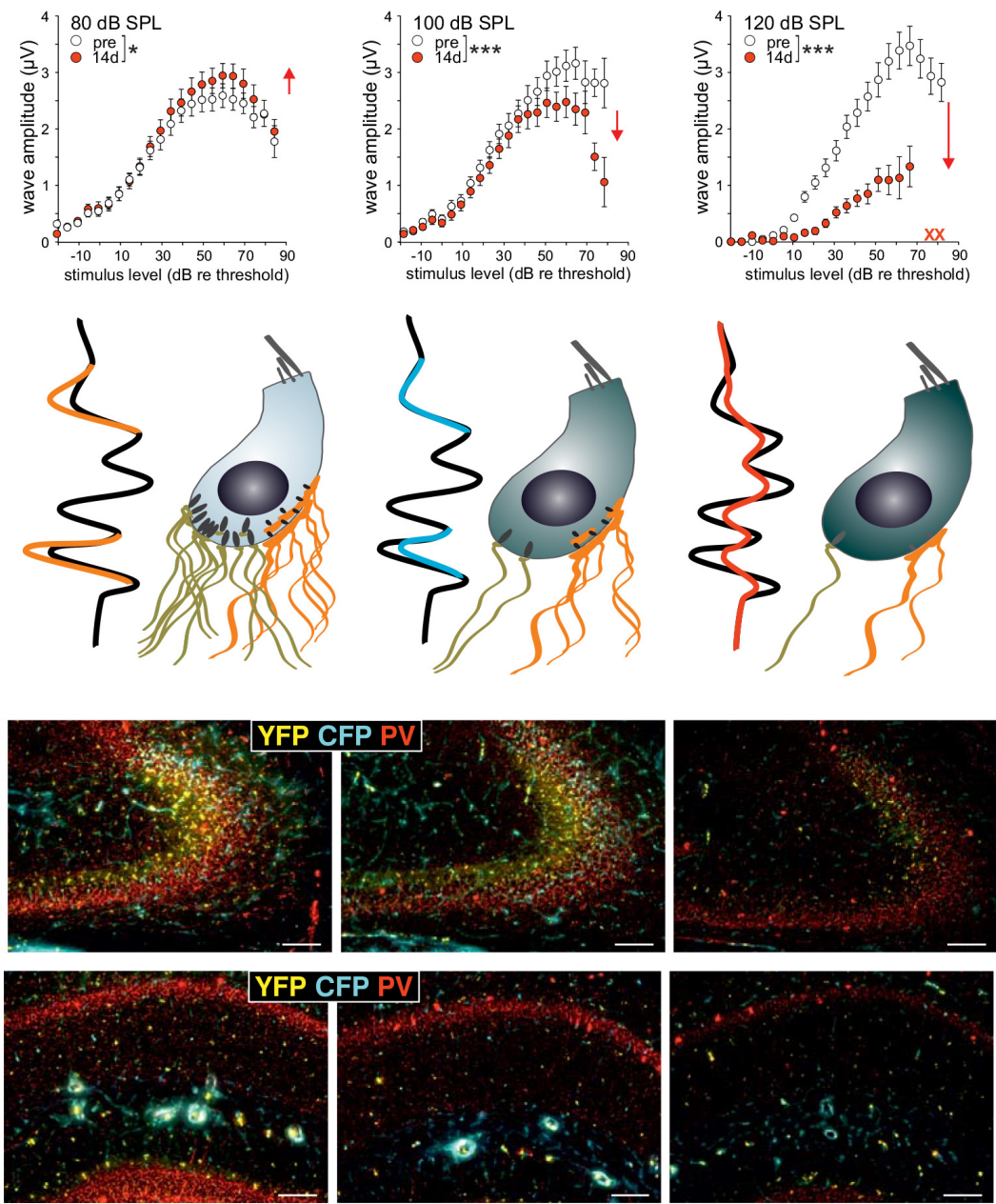

80 dB SPL

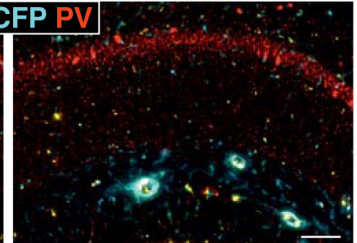

100 dB SPL

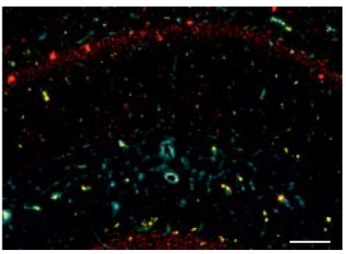

LTP CA1
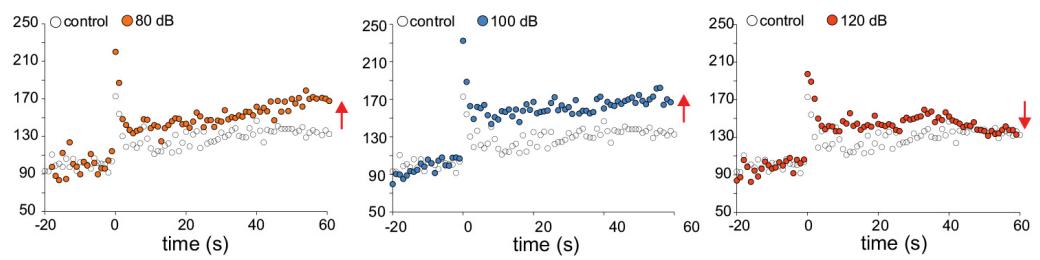

FIGURE 4 | (A) ABR wave I responses are enhanced after sound exposure of $80 \mathrm{~dB}$ SPL and reduced after $100 \mathrm{~dB}$ SPL stimulation which can be compensated on the level of the ABR wave IV (see B), while ABR wave I amplitudes decrease after $120 \mathrm{~dB}$ SPL exposure. (B) ABR wave I amplitude changes are linked to changes in $\mathrm{IHC}$ ribbons that are mostly preserved after sound enrichment ( $80 \mathrm{~dB} \mathrm{SPL}$ ), but decline following mild acoustic trauma (100 dB SPL). In contrast, following severe stressful acoustic trauma (120 dB SPL), ribbon loss exceeds $50 \%$, pointing to a loss of high-SR auditory fibers. (C,D) This goes along with marked increases in PV (red), Bdnf exon IV transcripts in capillaries (cyan), and exon VI transcripts in nerve endings (yellow), as can be observed in hippocampal CA3 (C) and CA1 (D) regions following 80 and $100 \mathrm{~dB}$ SPL, but not following $120 \mathrm{~dB}$ SPL exposure (Matt et al., 2018). (E) Significantly increased LTP observed after 80 dB SPL and $100 \mathrm{~dB}$ SPL, but not after $120 \mathrm{~dB}$ SPL sound exposure compared to that of the controls. Scale bars in (B,C) indicate $100 \mu \mathrm{m}$. Modified after Matt et al. (2018). SP, stratum pyramidale; SR, stratum radiatum; FH, fissura hippocampi; SM, stratum moleculare; SL, stratum lucidum.

associated with enhanced $B d n f$ exon IV transcripts in capillaries in the stratum lucidum (Figure $4 \mathrm{C}$, cyan in SL). Also, PVIN levels in perisomatic localization in the CA1 region were enhanced (Figure 4D, red) and linked with reduced PV-IN levels in dendritic localization [not shown, (Matt et al., 2018)], which together led to elevated hippocampal LTP (Figure 4E). When BLEV mice were exposed to stressful acoustic trauma of $120 \mathrm{~dB}$ SPL, however, that led to critically diminished numbers of high-SR auditory nerve fibers (judged from IHCs ribbon loss exceeding $>50 \%$ ), persistently reduced ABR wave IV amplitudes 
(Matt et al., 2018), failed recruitment of activity-dependent $B d n f$ transcripts, lowered hippocampal perisomatic PV-IN levels, and lower LTP levels were observed (Figures 4C-E, right panels) (Matt et al., 2018). This suggested that maintained fast (highSR) auditory fiber processing is critical for central activitydependent BDNF recruitment during homeostatic increased central neural gain. Particularly stressful acoustic trauma had, in previous studies, already been shown to lead to failed central neural gain that was linked to changes in hippocampal plasticity gene expression (Rüttiger et al., 2013; Singer et al., 2013; Matt et al., 2018).

Previous studies linked impaired $B d n f$ exon IV or VI transcripts with deficits in cognition and memory (Sakata et al., 2010; Vaghi et al., 2014; Mallei et al., 2015; Hill et al., 2016), together with deficits in cortical inhibition (Hong et al., 2008; Knipper et al., 2021), but this needs to be reconsidered in future studies with regard to deficiencies in the specific driving force for activating BDNF and inhibitory PV-IN activity.

\section{ALTERED EXCITATION AND INHIBITION IN ACUTE ACOUSTIC TRAUMA, DEAFNESS, AND TINNITUS: LOST FAST AUDITORY PROCESSING}

Hyperexcitability linked to reduced inhibition has also been observed in acquired deafness, congenital deafness, and tinnitus. The imbalance in excitation and inhibition in these auditory impairments is often interpreted as a compensatory response to auditory deprivation linked to increased central neural gain or an adaptive rewiring process. Here, we reconsider the imbalances of excitation/inhibition in these cases in the context of a loss of tonic inhibitory strength (Box 3 ), which can contribute to hearing disorders through decreased discharge population synchrony (enhanced variability) and a diminished signal-to-noise ratio following less developed or reduced fast (high-SR) auditory nerve fiber processing.

\section{Lost Fast Auditory Processing Following Acquired Deafness, Acoustic Trauma, or Tinnitus}

Imbalances in excitation and inhibition are observed in acquired deafness, which can be caused by cochlear damage, middleear ossicle removal, acoustic trauma, or drug-induced deafness (Kotak et al., 2013; Mowery et al., 2019). In previous studies, it was shown that acquired deafness in mature animals led to hyperexcitability that coincided with a decrease in GABA and glutamic acid decarboxylase (GAD65) (Bledsoe et al., 1995; Abbott et al., 1999). Acquired deafness was linked with enhanced glutamatergic transmission, as shown in the superior olivocochlear complex or the midbrain (Potashner et al., 1997), with reduced glycinergic inhibition (Suneja et al., 1998; Potashner et al., 2000) or with decreases in GAD65 (Milbrandt et al., 2000). For the adult gerbil IC, it was shown that after monaural deafening, increased excitation occurred very quickly (McAlpine et al., 1997), even within a few minutes of deafening of the contralateral ear (Mossop et al., 2000). This fast time scale argues against a rewiring process or compensating refinement as causes of the enhanced excitability (Mossop et al., 2000). The rapid occurrence of increased excitation after deafening (Mossop et al., 2000) pointed rather to faster events, such as an acute switch of the GABAergic responsiveness from inhibitory to depolarizing activity (see also Section "Maturation of GABAResponsive Neurons Prior to Hearing Onset"). Not yet analyzed in the short-term, a re-emergence of depolarizing GABAergic signaling and decline of KCC2 has been observed 3-30 days after auditory nerve transection (Tighilet et al., 2016). In addition, a rapid decline of KCC2 and a re-emergence of depolarizing GABAergic signaling has been observed within minutes during pathological epileptic firing (Khirug et al., 2010; Lee et al., 2011; Nardou et al., 2011), a feature that may be noted in future studies in the context of sudden deafness. Previous studies reported that a majority of subjects with acquired, single-sided sudden deafness experienced tinnitus on the affected side (Lee et al., 2017). Also, in patients with normal maturation of the auditory pathway who experienced acquired sudden sensorineural hearing loss, tinnitus regularly occurs, with a prevalence of $60-90 \%$, often on the deaf side (Van de Heyning et al., 2008; Chadha et al., 2009; Eggermont and Kral, 2016). Not surprising in this context, tinnitus-inducing acoustic trauma has been linked with hyper-excitability and disinhibition, as observed in the cochlear nucleus (Dehmel et al., 2012; Koehler and Shore, 2013; Auerbach et al., 2014; Gao et al., 2016), in the IC (Chen and Jastreboff, 1995; Bauer et al., 2008), in the medial geniculate body (MGB) (Kalappa et al., 2014), or in the auditory cortex (Norena and Farley, 2013; Eggermont and Tass, 2015). In the majority of tinnitus studies, the elevated spontaneous activity, or hyperexcitability and reduced inhibition, was discussed in the context of an increased central neural gain [see reviews: (Schaette and Kempter, 2006, 2012; Norena, 2011; Schaette and McAlpine, 2011; Auerbach et al., 2014; Sedley et al., 2016; Shore et al., 2016; Roberts, 2018; Roberts and Salvi, 2019].

Other studies showed that tinnitus is more linked to impaired homeostatic adjustment processes (Zeng, 2013; Knipper et al., 2015; Auerbach et al., 2019; Möhrle et al., 2019; Sedley, 2019) than to an increase in central neural gain [see for a review (Knipper et al., 2013, 2020, 2021; Zeng, 2020)]. This was first observed in rodent models of tinnitus (Rüttiger et al., 2013; Singer et al., 2013) and confirmed in patients (Hofmeier et al., 2018, 2021; Möhrle et al., 2019; Refat et al., 2021). In tinnitus patients, the delayed and reduced $A B R$ wave $V$ was shown to be accompanied by reduced blood-oxygen-level-dependent (BOLD) fMRI (functional Magnet Resonance Imaging) responses in the MGB, and in the primary auditory cortex and hippocampal regions (Hofmeier et al., 2018, 2021). It was speculated that a loss of fast auditory processing in the tinnitus frequency channels (Figure 5, crossed high-SR in orange) contributes through diminished tonic inhibitory strength (Box 3) of PV-IN (Figure 5, enhanced green crosses, reduced orange minus) to elevated response variability, reduced spike reliability and reduced signal-to-noise ratio (Zeng, 2020) in affected frequency regions (Figure 5, elevated SRF baseline red dashed line, enhanced green crosses). The relation of lost tonic inhibitory strength to reduced signal-to-noise ratio was, meanwhile, confirmed in numerous 


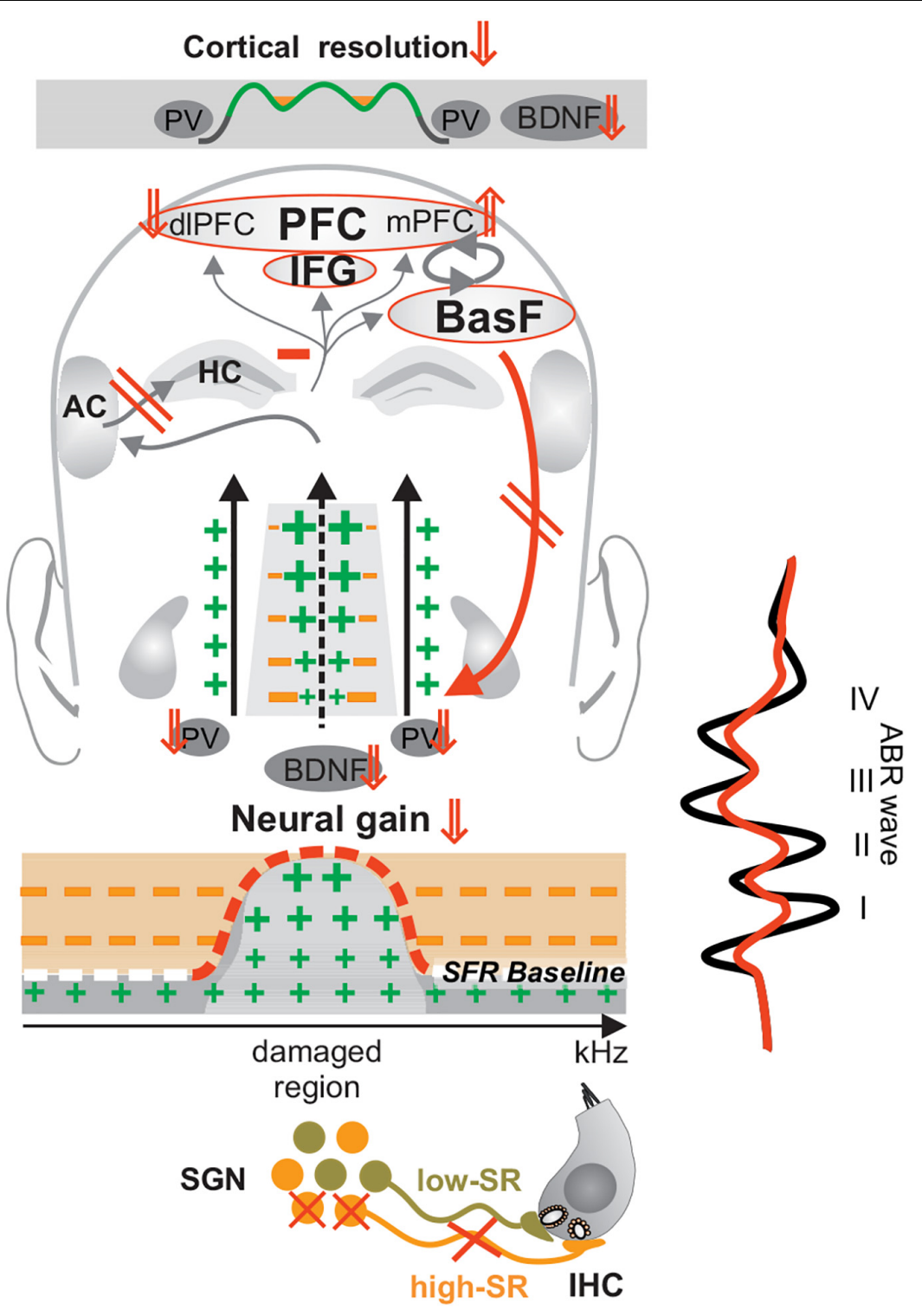

FIGURE 5 | Lost fast auditory processing following acquired deafness, trauma or tinnitus. A critical loss of high-SR fiber (orange fibers) firing may promote the re-emergence of hyperexcitability (enhanced green crosses) in affected frequency regions through the loss of tonic inhibitory PV-IN activity (reduced orange minus) subsequent to a decrease of recruitment of activity-dependent BDNF. The subsequent elevation of basal spontaneous firing rates suggests an unbalanced prefrontal stress control (mPFC介, dIPFC $\Downarrow$, negative feedback mechanism, and red downward arrow), which may contribute to a lack of compensation of altered auditory input (red ABR wave), further alertness and distress to, e.g., manifestations of phantom noise. Modified after Knipper et al. (2020). IHC, inner hair cell; SGN, spiral ganglion neuron; SFR, spontaneous firing rate; HC, hippocampus; IFG, inferior frontal gyrus; BasF, basal Forebrain; PFC, prefrontal cortex; dIPFC, dorsolateral PFC; mPFC, medial PFC; AC, auditory cortex; PV, parvalbumin.

studies. Thus, e.g., optogenetic suppression of PV-IN activity, led to reduced task performance and reduced signal-to-noise ratio linked to increased baseline spontaneous gamma power and occlusion of changes in evoked gamma power (Chen et al., 2017). Also, a pharmacological PV-IN activation was previously shown to have the potential to diminish noise-induced tinnitus in animal studies (Deng et al., 2020). Moreover, reduced PVdensity, but not somatostatin-positive interneurons density, in the primary auditory cortex was reported in tinnitus-perceiving animals (Masri et al., 2021). Regarding the tight correlation of
BOLD to high-frequency gamma oscillations (Zumer et al., 2010; Butler et al., 2017), we thus speculate that the reduced and delayed $\mathrm{ABR}$ wave $\mathrm{V}$ and reduced BOLD fMRI responses in the auditory cortex observed in tinnitus patients (Hofmeier et al., 2018, 2021) may be the result of diminished tonic PV-IN strength, which through diminished discharge population synchrony, reduced spike reliability and enhanced spike variability (Cardin et al., 2009; Pi et al., 2013; Kim et al., 2016; Chen et al., 2017) may have contributed to an enhanced perception of internal noise (Knipper et al., 2020; Zeng, 2020). 
If we question how, in the case of tinnitus, the internal noise can be heard as a disturbing sound, the observation becomes crucial that the tinnitus group exhibited not only reduced evoked fBOLD in the auditory cortex, but also elevated positive resting state connectivity ( $\mathrm{r}-\mathrm{fcMRI}$ ) of default mode network activity, including the prefrontal cortex regions (PFC) (Hofmeier et al., 2018). In the tinnitus group, elevated $r$-fcMRI correlations were observed in the medial PFC (Hofmeier et al., 2018), a brain region said to be linked to stress excitation (McKlveen et al., 2013, 2016; Utevsky and Platt, 2014). This elevated r-fcMRI connectivity in mPFC correlated with the reduced sound-induced BOLD fMRI activity in the MGB (Hofmeier et al., 2018) and this reduced activity, in turn, correlated with increased latencies of the ABR wave $\mathrm{V}$ responses (Hofmeier et al., 2018) (Figure 5, mPFC $\Uparrow$ ). Together, this points to an unbalanced extra-hypothalamic prefrontal (PFC) and hippocampal stress control (Sullivan and Gratton, 2002; Meltser and Canlon, 2011; Canlon et al., 2013; de Kloet, 2014; Irvine, 2018b; Viho et al., 2019). This unbalanced HPA stress control is suggested to contribute to further alertness and distress due to the phantom noise (Knipper et al., 2020, 2021).

Interesting in this context is that lower BDNF activation was previously associated with enhanced distress levels in tinnitus patients that suffered from BDNF $\mathrm{Val}^{66} \mathrm{Met}$ polymorphism (Vanneste et al., 2018). Also, reduced activity-dependent BDNF recruitment, linked with impaired glucocorticoid receptor phosphorylation was shown to lead to impaired long-term memory retention and to deficits in forming postsynaptic dendritic spines, for example after motor-skill training (ArangoLievano et al., 2019). This means that diminished fast auditory processing (Figure 5, crossed high-SR fibers in orange) in distinct affected frequency regions could, through reduced activity-dependent BDNF (Figure 5, BDNF $\Downarrow$ ), lead to diminished PV-IN inhibitory strength (Figure 4, PV $\Downarrow$ ) and subsequent elevated SFR (Figure 5, SFR $\Uparrow$, red dashed line). The reduced activity-dependent BDNF recruitment in frontal brain regions would further diminish hippocampal responsiveness and diminish extra-hypothalamic prefrontal (PFC)/hippocampal stress control, and thus enhance alertness to the 'brain noise.' A previously suggested negative feedback of stress-receptor activation particular to fast auditory nerve response vulnerability (Singer et al., 2013, 2018a) (Figure 4) would accelerate the self-reinforcing downward spiral towards the increased stress and anxiety of tinnitus patients. Distress is, meanwhile, the best predictor of tinnitus severity, and a stronger predictor for tinnitus than any demographic factors (Crönlein et al., 2016; Beukes et al., 2021).

\section{Failed Maturation of Fast Auditory Processing Following Congenital Deafness}

Numerous studies have analyzed hearing loss prior to hearing onset induced by kainate injection or ossicle destruction. Inhibitory neuronal markers were significantly diminished (Milbrandt et al., 2000; Mossop et al., 2000), whereas the excitability of various ascending central auditory neurons was significantly increased (Nordeen et al., 1983; Kitzes, 1984;
Kitzes and Semple, 1985; Popelar et al., 1994). Also, cochlear ablation prior to hearing onset (Sanes et al., 1992) or deafness in the deafness $(d n / d n)$ mutant mouse (Oleskevich and Walmsley, 2002) led to larger EPSP amplitudes and lower inhibitory synaptic strength. This phenomenon was observed in the cochlear nucleus (Oleskevich and Walmsley, 2002), in the lateral lemniscus, and in IC neurons (Sanes et al., 1992), as well as in thalamocortical and intracortical primary auditory cortex neurons (Kotak et al., 2005, 2013; Mowery et al., 2019). It was suggested that the larger EPSP amplitudes in congenital deafness may result from an increase in AMPA- and non-NMDA receptors and a decrease in inhibitory postsynaptic potential conductance. In another deaf Vglut $^{-/-}$animal model, where glutamate release from IHCs is abolished due to deletion of vesicular glutamate transporter 3 (VGlut3) (Seal et al., 2008), elevated spontaneous activity, with longer bursts and smaller spikes, was recorded from cochlear (Babola et al., 2018; Sun et al., 2018) and from IC neurons (Babola et al., 2018). Since an enhanced excitability was seen in the IC neurons of VGlut $3^{-/-}$mice, even when the auditory cortex neurons were ablated, a top-down modulatory effect as the source for the enhanced central excitability could be excluded (Babola et al., 2018). In general, in these different cases of congenital deafness, the enhanced excitability in the ascending pathway were interpreted as an adaptive response to auditory deprivation (Babola et al., 2018) as a result of central rewiring (Nordeen et al., 1983; Moore, 1994), or as a compensatory response to the absence of synaptic activity (Davis and Bezprozvanny, 2001; Oleskevich and Walmsley, 2002) due to maladaptive central synaptic refinement (Ortmann et al., 2011). We propose that the enhanced excitability in the ascending auditory pathway in congenital deafness is neither the result of a long-term wiring process nor a compensatory response to the absence of central synaptic refinement, but rather may reflect inappropriate inhibitory shaping of auditory nerve fibers through efferent feedback control, possibly contributing to a failed switching of GABA-responsive neurons from depolarizing to hyperpolarizing activity prior to the onset of hearing (Lohrke et al., 2005) (Figure 6, see also Section "Maturation of GABA-Responsive Neurons Prior to Hearing Onset"). It may also indicate a failure of a proper maturation of fast (high-SR) auditory processing in the absence of auditory experience.

For congenital deafness in humans, this would inspire the question about a critical time period for the restoration of hearing through cochlear implants (CI); i.e., if not restored early enough, do the relevant auditory brain circuits remain in a stage of insufficient inhibitory strengths that hampers precise sharpening of receptive fields and proper inhibitory strength in the finegrained microcircuits required for speech discrimination and temporal coding (Oxenham, 2018; Kral et al., 2019; Thompson et al., 2021)? The immediate onset of tinnitus that occurred in $60-90 \%$ of cases in children with cochlear implants when the implants were not in use (Van de Heyning et al., 2008; Chadha et al., 2009), may indicate that constant electrical stimulation through CIs is required to suppress 'internal noise' and to 'silence' phantom noise (Knipper et al., 2020). Recalling, moreover, that CIs in children are implanted on average at the age of 1-2 years (Peterson and Bergeson, 2015; Easwar et al., 2017), postponing 


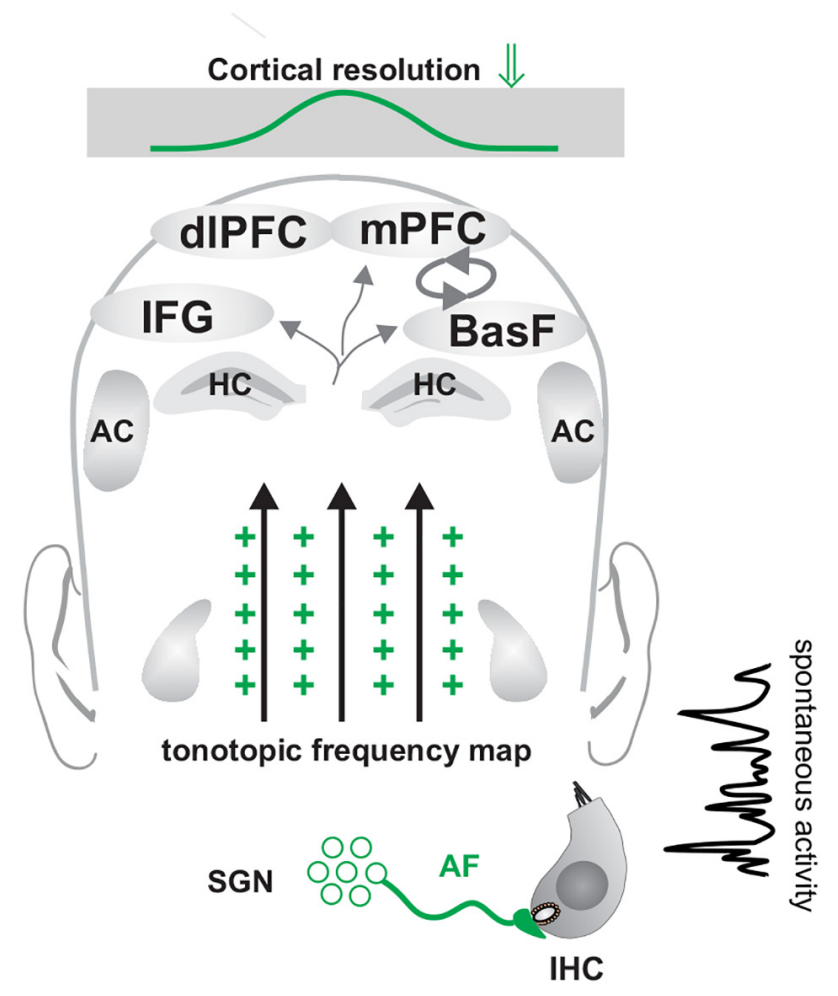

FIGURE 6 | Enhanced excitability in the ascending auditory pathway (green crosses) in congenital deafness may reflect the maturational stage of the initial hyperexcitability (green crosses) in the ascending auditory pathway, when spontaneous firing dominates and fast (high-SR) auditory processing has not yet matured. During that time period, GABA-responsive neurons respond with depolarizing instead of hyperpolarizing activity. Modified after Knipper et al. (2020). IHC, inner hair cell; SGN, spiral ganglion neuron; HC, hippocampus; IFG, inferior frontal gyrus; BasF, basal Forebrain; PFC, prefrontal cortex; dIPFC, dorsolateral PFC; mPFC, medial PFC; AC, auditory cortex.

the first auditory experience in these CI-carriers by $1-1.5$ years (Sharma et al., 2002; Petersen et al., 2015) might induce a delay that is too long for some maturation steps. A judgment about a critical delay of auditory experience for proper implementation of distinct developmental steps may be assessed by looking at the prevailing deficits described in congenitally deaf CI-carriers. Deficits in CI-carriers include a reduction in binaural sound localization (Hamalainen et al., 2011; Lazard et al., 2012; Petersen et al., 2013; Slugocki and Trainor, 2014), missing left-hemisphere dominance (Petersen et al., 2013; Peterson and Bergeson, 2015; Easwar et al., 2017), weaker pitch sensitivity (Houtsma and Smurzynski, 1990; Kaernbach and Bering, 2001), lower dynamic range and higher thresholds (Sharma et al., 2002; Deroche et al., 2014), as well as lower mismatch negativity amplitudes, and prolonged CI-evoked cortical auditory evoked potential latencies (Ponton and Eggermont, 2001; Sharma et al., 2002).

To date, the latency of the auditory cortical component $\mathrm{P}_{1}$, which is used as an objective measure of developmental hearing experience (Sharma et al., 2005a,b), were reported to be shorter in early-implanted deaf children as compared to late-implanted children (Sharma et al., 2005a). This already points to a critical time window of CI implantation to achieve temporal precise hearing. The less variable performance, the reduced expansion of activated areas at the primary auditory cortex, and less exuberant connections between the visual cortex and auditory cortex in early- versus late-implanted congenitally deaf cats (Lomber et al., 2010; Land et al., 2016; Kral et al., 2019) point to critical time windows for CI implantation. In such cases, a possibly immature stage of cortical inhibitory shaping with incompletely accomplished clustering and pattern segregation of auditoryspecific modalities may be considered.

It is likely that documented deficits in CI-carriers, such as in latency shift, sound localization, or pitch sensitivity, may critically depend on fast auditory processing and possibly on proper high-SR auditory fiber processing. Even missing left hemisphere dominance (Petersen et al., 2013; Peterson and Bergeson, 2015; Easwar et al., 2017) may be related to the strong impact that neuronal activity and sensory experience is predicted to have on the proliferation and differentiation of oligodendrocytes during myelination (Xin and Chan, 2020). Keeping this in mind, there is a distinct need for the influence of fast (high-SR) auditory processing on myelination progress to be urgently tested in future studies. In the course of hearing restoration through successful implementation of CIs or hearing aids, attempts should be made to monitor the implementation of proper inhibitory strength.

\section{ALTERED EXCITATION AND INHIBITION FOLLOWING DIMINISHED FAST AUDITORY PROCESSING LINKED TO 'CENTRAL' HEARING LOSS}

\section{Failed Fast Auditory Processing in Autism Spectrum Disorders}

An excitation/inhibition imbalance is also considered to be a characteristic feature of ASD, which is accompanied by reduced PV-IN labeling (Takano and Matsui, 2015; Pirone et al., 2018; Goel et al., 2019), elevated levels of the activityrelated gene Arg3.1/Arc (Korb and Finkbeiner, 2011; Goel et al., 2019; Eckert et al., 2021), or by increased fEPSPs (Mohn et al., 2014). A reduced inhibition linked with reduced levels of GABA-synthetisising enzymes and GABA receptors was observed in the brain of patients with ASD (Fatemi et al., 2002, 2009, 2010; Reynell and Harris, 2013; Schur et al., 2016; Cukier et al., 2020). In autism patients and animal models, the reduced inhibition is said to reduce reliability (increasing variability) of signal transformation and the signal-to-noise ratio (Dinstein et al., 2012; Haigh et al., 2016). Interestingly, deficits in fast auditory processing are also reported in nearly normal-hearing children that have ASD (Fitch et al., 2013; Foss-Feig et al., 2017), and here, deficits in fast auditory processing are linked to markedly delayed and displaced auditory steady-state responses (Stroganova et al., 2020), or with rapid spectral-ripple discrimination deficits (Ankmnal Veeranna et al., 2019).

A previous study in a mouse model with a cell-specific deletion of $B d n f$ in Pax2 positive GABAergic precursor cells 
(Bdnf ${ }^{P a x 2}$ KOs mice) showed an autism-like phenotype (Eckert et al., 2021). These mice exhibited normal basal hearing function, but with reduced and delayed ABR wave IV, diminished PVIN labeling in the auditory cortex and hippocampus, and with reduced tonic inhibitory strength and elevated spontaneous firing rates in dorsal cochlear nucleus (Eckert et al., 2021) and IC neurons (Chumak et al., 2016). These features were associated with a reduced (sound)-induced LTP/LTD adjustment, impaired learning, deficits in social behavior, and enhanced anxiety and stress levels (Eckert et al., 2021). This phenotype thus pointed to a diminished extra-hypothalamic stress control (de Kloet et al., 2019). Impaired PV-IN mediated inhibitory shaping of auditory and hippocampal circuits, as observed in $B d n f^{P a x 2} \mathrm{KOs}$, was moreover suggested to lead to impaired central neural gain after sound enrichment, deficits in LTD, and pathologically increased activity-related gene Arc expression (Eckert et al., 2021). Proper LTD and balanced Arc expression levels are crucial for the control of fast changes in AMPA receptor trafficking during novelty discrimination (Derkach et al., 2007; Waung et al., 2008; Blair et al., 2019; Penrod et al., 2019; Roth et al., 2020).

This finding emphasizes that deficits in fast auditory processing, leading to diminished tonic inhibitory strength, can impair central neural gain and affect not only temporal coding but also cognitive functions, including novelty discrimination tasks and learning.

Deficits in fast auditory processing may be uniquely critical in the auditory system, which in comparison to other senses relies particularly on narrow time windows and a high speed of information flow (Zajac and Nettelbeck, 2018). To further validate a causal relationship between failed maturation of fast auditory processing and the autism phenotype, it will be necessary to explore in more detail the fine-structure of $\mathrm{ABR}$ and auditory steady-state responses, in combination with functional electroencephalography (EEG), and fMRI in animal models and children with autismspectrum disorders.

\section{Failed Fast Auditory Processing During Age-Dependent 'Central' Hearing Loss}

A link between deficits in fast auditory processing and agerelated deficits in cognition has previously been proposed. Thus, studies analyzing aging animals showed that, independently of age or hearing thresholds, animals fell into two groups regarding central auditory responses to cochlear synaptopathy: The 'high-compensating' group was able to respond to cochlear synaptopathy with an enhanced input/output function (elevated ABR wave IV/I ratio), linked with enhanced LTP and maintained temporal processing (Eckert et al., 2021) (Figure 7A, left panel). The other, the 'low-compensating' group, exhibited weakened compensatory capacity (lower ABR wave IV/I ratio), linked with lower LTP, and weakened temporal coding (Marchetta et al., 2020) (Figure 7B, right panel). The reduced capacity to centrally compensate age-dependent cochlear synaptopathy, and the lower hippocampal LTP with attenuated temporal coding, was associated with a prolonged latency of the auditory nerve response (ABR wave $\mathrm{I}$ ) in comparison to the high-compensating group (Marchetta et al., 2020), suggesting that fast (highSR) auditory processing was mitigated in this group. In the 'low-compensating group', moreover, lower levels of $B d n f$ IV and VI transcripts were seen in hippocampal nerve terminals and capillaries in comparison to the high-compensating group, (Figures 7C,D, compare yellow and cyan staining). Although differences in auditory response latencies, auditory neural responses to modulated tones, and LTP may point to differences in inhibitory strength following differential impairment of fast auditory fiber processing (Marchetta et al., 2020), experimental evidence for this is currently missing. Reduced GABAergic activity was, however, previously observed in ascending auditory circuits, e.g., during aging, a phenomenon that was hypothesized to be linked to cognitive decline (Ibrahim and Llano, 2019; Pal et al., 2019; Rogalla and Hildebrandt, 2020). In these cases also, it may be useful to consider deficits in fast auditory processing as being causally related to age-dependent hearing loss that is associated with cognitive deficits.

\section{COUPLING OF INHIBITORY/EXCITATORY CIRCUIT ACTIVATION TO CEREBRAL BLOOD FLOW}

\section{The Role of GABAergic Activity for Neurovascular Coupling}

In questioning whether reduced tonic inhibitory strength following fast auditory processing may be particularly critical for cognition, as predicted from autism animal models (see Section "Failed Fast Auditory Processing in Autism Spectrum Disorders"), the critical time period of maturation of fast auditory processing and inhibitory strength in auditory and associated limbic circuits - between the 2nd and 3rd postnatal week in rodents (Itami et al., 2007; Eckert et al., 2021) needs to be reconsidered. In rodents, this time period overlaps with the time of progressively faster BOLD signals, in which brain regions manifest an increased intensity in response to sensory stimulation (Colonnese et al., 2008). Thus, before P11 in rodents (prior to hearing onset), brain activation is not associated with sustained increases of the cerebral blood flow (CBF), which would result in none or a negative BOLD signal (Colonnese et al., 2008; Kozberg et al., 2013; Iadecola, 2017). Only in the 2nd and 3rd week does neural activity lead to increasingly faster and more intense hemodynamic responses, as shown by BOLD fMRI (Colonnese et al., 2008; Iadecola, 2017). The increased hemodynamic BOLD fMRI response during this critical time period is linked with pronounced neurovascular and systemic changes, including increases in vascular density, synaptogenesis, energy metabolism, and sensitivity of the cerebral microcirculation to vasoactive stimuli (Nehlig et al., 1989; Colonnese et al., 2008; Goyal et al., 2014; Engl et al., 2017; Iadecola, 2017). The time of increased hemodynamic BOLD fMRI responses is also the time when in rodents, long-term potentiation in the hippocampus gradually matures (Ostrovskaya et al., 2020). 


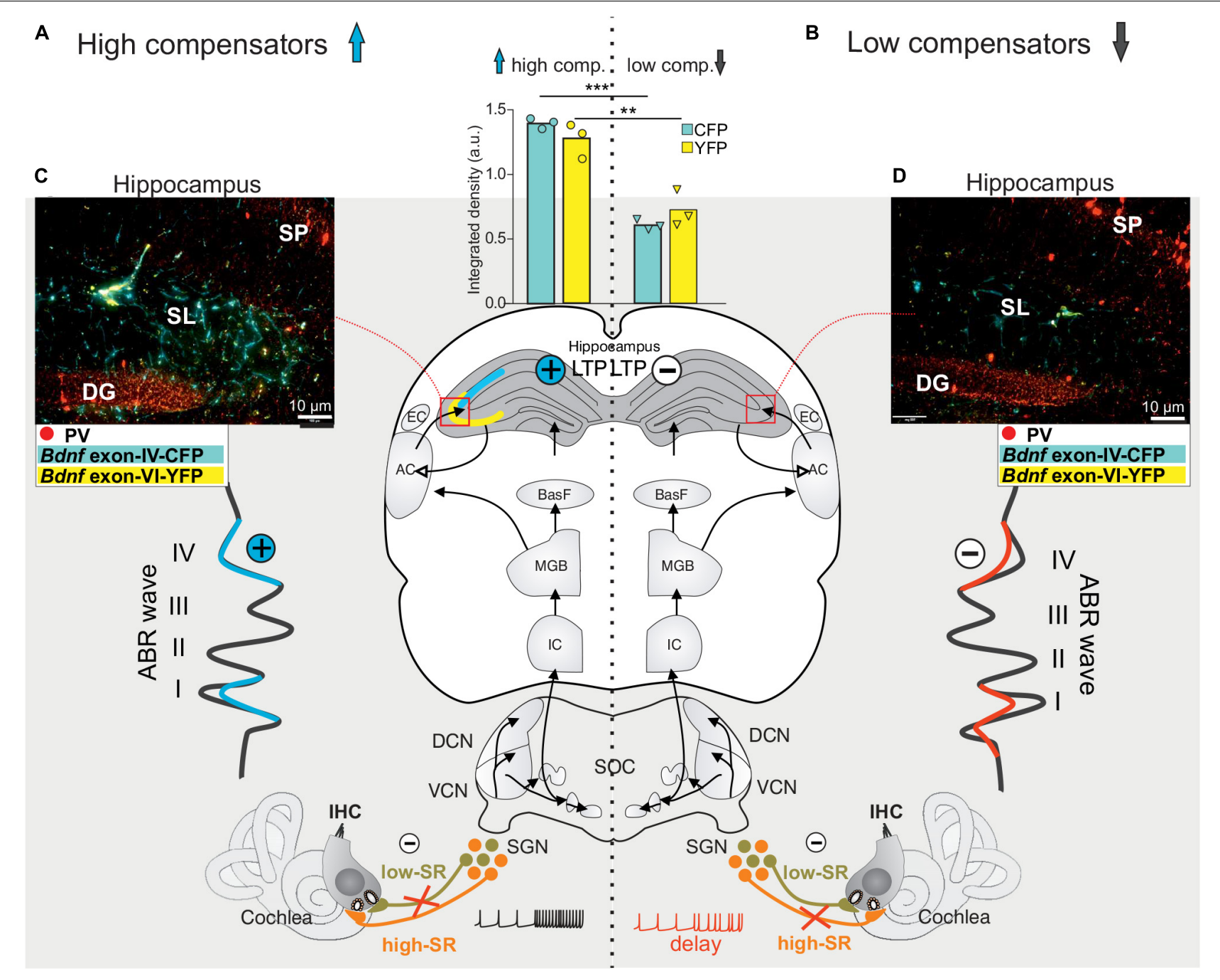

FIGURE 7 | Schematic presentation of high and low central compensatory mechanisms in the aging auditory system. (A) Independent of aging or differences in hearing thresholds, cochlear synaptopathy can differ, depending on whether de-afferentation due to low-SR auditory nerve fiber loss dominates (A, low-SR in light green) or high-SR auditory nerve fiber loss dominates (B, high-SR in orange). In the first case, an ABR wave I reduction is associated with disproportionally increased ABR wave IV amplitude (A, left blue amplitude, plus in blue circle), with elevated Bdnf exon IV (cyan) and exon VI (yellow) expression in hippocampal circuits (C, left panel and bar graph) and higher hippocampal LTP (plus in blue circle). In the case of a critical loss of fast (high-SR) auditory nerve fiber processing (B, high-SR in orange), an attenuated temporal resolution capacity of auditory nerve fibers (B, delay) is associated with permanently decreased ABR wave IV amplitude (B, red amplitude, minus in white circle), decreased recruitment of hippocampal Bdnf exon IV and exon VI transcripts (D, right panel and bar graph) and significantly lower LTP mobilization (minus in white circle). ABR, auditory brainstem response; IHC, inner hair cell; VCN, ventral cochlear nucleus; DCN, dorsal cochlear nucleus; SOC, superior olivary complex; IC, inferior colliculus; MGB, medial geniculate body; BasF, basal Forebrain; AC, auditory cortex; EC, entorhinal cortex; PV, parvalbumin.

We questioned whether the maturation of fast (high-SR) auditory processing, of inhibitory PV-IN microcircuits, of hemodynamic BOLD fMRI responses, and of LTP may not only be correlated in time, but also functionally. More precisely, we asked whether the imbalances in excitation and inhibition in hearing disorders that correlated with reduced tonic inhibitory strength, as predicted in the case of impaired fast auditory nerve fiber responses (Chumak et al., 2016; Eckert et al., 2021), might also have implications for hemodynamic responses.

This hypothesis is based on new insights into the mechanism of hemodynamic responses: Previously, glutamatergic neuronal activity was assumed to mainly trigger hemodynamic responses and vasodilation during a bilateral homeostatic response: Glutamatergic neuronal activity, such as neural feedforward signaling, includes neuronal-derived nitric oxide (NO) release from the glutamatergic synapses that causes a metabolic feedback signal in smooth muscle cells of parenchymal arterioles, finally leading to vasodilation [for a review see Attwell et al. (2010); Kisler et al. (2017); Ledo et al. (2021)]. Newer findings, however, suggest that arteriole vasodilation may possibly occur independently of NO (Chow et al., 2020). In line with this, neurovascular coupling is preserved in mice lacking endothelial NO synthase (Girouard et al., 2007). Also, a release of NO from GABAergic interneurons was shown to affect the hemodynamic 


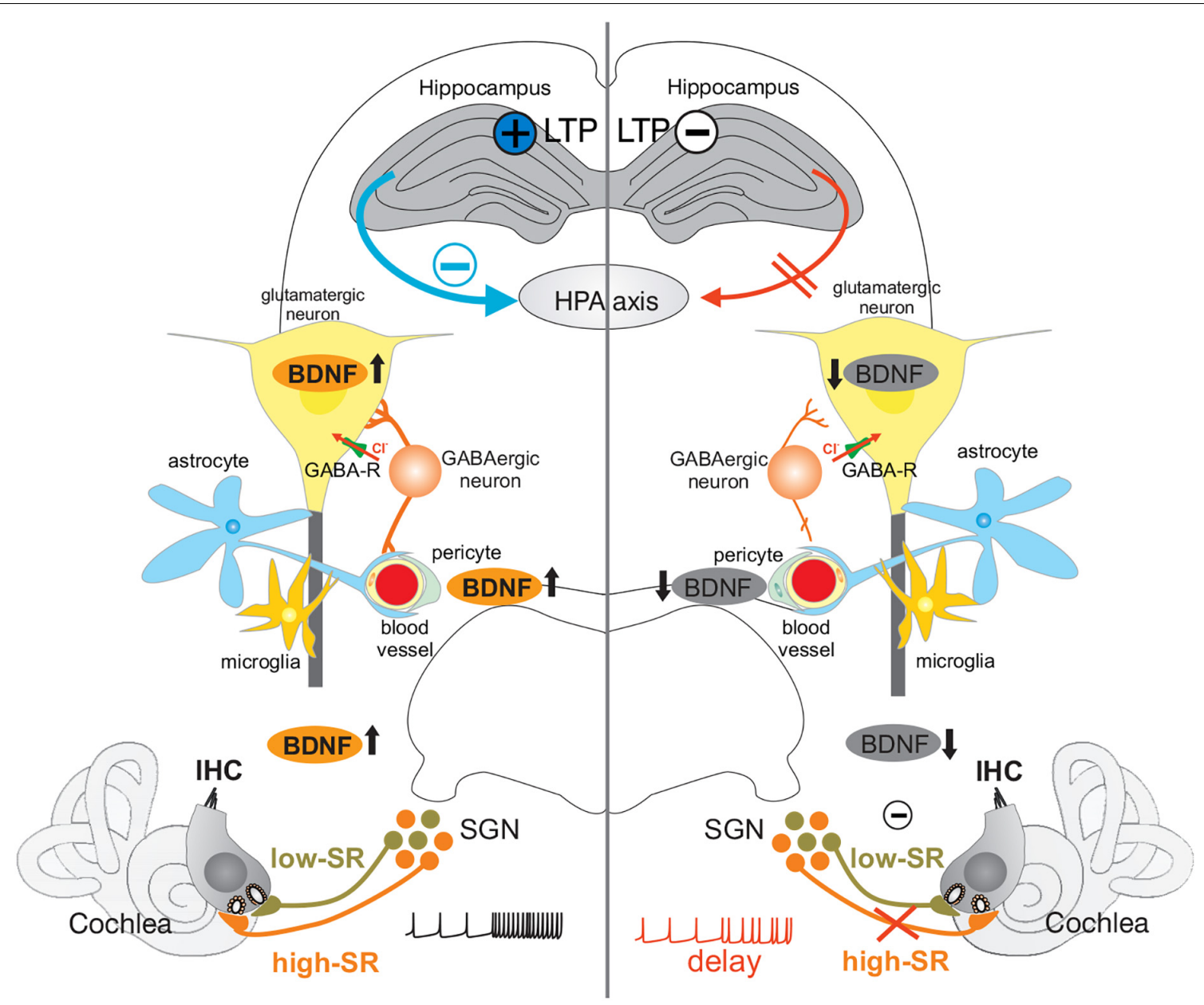

FIGURE 8 | Under healthy conditions (Left), fast auditory processing (high-SR in orange) enables context-specific information processing in auditory and associated circuits (hippocampus, HPA axis) through upregulation of activity-dependent BDNF ( $\uparrow$ ). Increased central neural gain, represented by increased hippocampal LTP (black cross in blue circle), allows the facilitation of BDNF/PV-IN circuits by BDNF $\uparrow$ in glutamatergic neurons, and an increase in perisomatic inhibitory strength (GABAergic neuron contacting glutamatergic neuron) dependent on increased stimulus responses. These in turn provide a balanced HPA axis control (blue arrow and minus) and local hemodynamic supply (blood vessels) for a long-lasting improved signal-to-noise ratio and stimulus discrimination above noise (black spike train). During aging, or following acoustic trauma, acute, or congenital deafness (Right), a critical loss of high-SR auditory nerve fibers (orange) occurs, leading to reduced auditory driving force and BDNF expression $(\downarrow)$. This is associated with reduced hippocampal LTP (black minus in white circle), reduced tonic-PV-IN strength (reduced synaptic contacts of GABAergic neurons on glutamatergic neurons), altered extra-hypothalamic stress control (red arrow to HPA axis), and possibly disturbed coupling of inhibitory neuronal activity to hemodynamic responses, leading to altered sound processing (red spike train). IHC, inner hair cell; SGN, spiral ganglion neuron; GABA-R, GABA receptor; HPA axis, hypothalamic-pituitary-adrenal axis; LTP, long-term potentiation; BDNF, brain-derived neurotrophic factor.

responses through the nitric-oxide sensitive guanylyl cyclase (NOsGC) pathway (Cauli et al., 2004; Kocharyan et al., 2008; Lee et al., 2020). These observations were corroborated by experiments employing an optogenetic activation of GABAergic interneurons, which provoked a significant increase in the CBF (Uhlirova et al., 2016; Iadecola, 2017; Vazquez et al., 2018). Also, optogenetic activation of GABAergic interneurons increased $\mathrm{CBF}$ even when glutamatergic GABAergic activity was pharmacologically blocked (Anenberg et al., 2015). Fast PV-IN are decisive in generating gamma-oscillations, as measured with EEG in combination with optogenetic techniques to stimulate PV-INs (Cardin et al., 2009; Sohal et al., 2009; Chen et al., 2017). Thus previous studies that found a significantly reduced gamma activity following stress events that lead to impaired neurovascular coupling (Sohal et al., 2009; Lee et al., 2015; Chen et al., 2017; Han et al., 2019) would also support the involvement of PV-IN GABAergic signaling on CBF. Interestingly, in this case, reduced GABAergic activity after stress occurred in nNOSpositive interneurons (Czeh et al., 2015, 2018; Csabai et al., 2018; Han et al., 2019), underscoring PV-IN activity as possibly contributing to NO-induced vasodilation.

The contradicting assumptions, that on the one hand NOrelease from GABA-IN may influence endothelia cells of blood vessels, and thereby change their diameter (Lee et al., 2020), while on the other hand arteriole vasodilation is suggested to occur independently of NO (Chow et al., 2020), may moreover find a rational solution through suggestions that put capillary dilation in the focus of hemodynamic responses, rather than 
smooth-muscle-cell arteriole dilation. Thus, capillary flow was recently suggested not to be a passive consequence of the flow in upstream smooth muscle-unsheathed arterioles, but vice versa; capillary dilation may be a primary event preceding arteriole dilatation (Kisler et al., 2017). In this scenario, capillary dilation would occur as a result of the relaxation of pericytes, and this local dilation would spread from capillaries toward larger arterioles in a secondary step (Hall et al., 2014; Lendahl et al., 2019; Han et al., 2020). A crucial role of pericytes for capillary vasodilation during hemodynamic responses has been shown in numerous previous studies (Lourenco et al., 2014; Sweeney-Reed et al., 2016; Caporarello et al., 2019; Alarcon-Martinez et al., 2020), although others failed to demonstrate this (Fernandez-Klett et al., 2010; Hill et al., 2015; Wei et al., 2016; Cudmore et al., 2017; Iadecola, 2017). On the other hand, pericytes have been shown to express NO-responsive enzymes (Friebe et al., 2018). Also, a pericyteinduced role for vasodilation through capillaries would become feasible, since the large surface area of capillaries and minimal changes in their diameter would produce a large change in blood flow (Han et al., 2020).

It is thus challenging to consider that the increase in PV-IN mediated inhibitory strength between the 2nd and 3rd postnatal week (Itami et al., 2007; Eckert et al., 2021) and the coinciding progressive changes in shape and intensity of BOLD signals (Colonnese et al., 2008) are functionally related events. While all these findings may support the notion that PV-IN have a potential to modulate $\mathrm{CBF}$, evidence for their participation in neurovascular coupling to physiological stimuli is still limited. We may, however, conclude that, in addition to glutamatergic neuronal activity influences on vasodilation (Attwell et al., 2010; Kisler et al., 2017; Ledo et al., 2021), PV-IN GABAergic activity may play a role in hemodynamic responses.

\section{CONCLUSION}

During aging or following acoustic trauma, acute or congenital deafness, a critical diminution of fast (high-SR) auditory driving force diminishes activity-dependent BDNF activities and tonicPV-IN strength, hippocampal LTP, extra-hypothalamic stress control and possibly proper coupling of inhibitory neuronal activity to hemodynamic responses, accelerating a negative feedback cycle (Figure 8, right side). Under healthy conditions (Figure 8, left side), when critical fast auditory processing

\section{REFERENCES}

Abbott, S. D., Hughes, L. F., Bauer, C. A., Salvi, R., and Caspary, D. M. (1999). Detection of glutamate decarboxylase isoforms in rat inferior colliculus following acoustic exposure. Neuroscience 93, 1375-1381. doi: 10.1016/s03064522(99)00300-0

Addleman, D. A., and Jiang, Y. V. (2019). Experience-Driven Auditory Attention. Trends Cognit. Sci. 23, 927-937. doi: 10.1016/j.tics.2019.08.002

Aid, T., Kazantseva, A., Piirsoo, M., Palm, K., and Timmusk, T. (2007). Mouse and rat BDNF gene structure and expression revisited. J. Neurosci. Res. 85, 525-535. doi: $10.1002 /$ jnr.21139

Alarcon-Martinez, L., Villafranca-Baughman, D., Quintero, H., Kacerovsky, J. B., Dotigny, F., Murai, K. K., et al. (2020). Interpericyte tunnelling nanotubes is maintained, context-specific information through specific activation of BDNF signaling in auditory and associated circuits, allow, through increased central neural gain, the facilitation of $\mathrm{BDNF} / \mathrm{PV}$-IN dependent increase stimulus responses that in turn guarantee a balanced HPA axis control and local hemodynamic supply for a long-lasting improved signal-to-noise ratio and stimulus discrimination above noise.

In view of the increasing evidence of a link between hearing loss and dementia, a better understanding of this possible relationship is an important challenge (Livingston et al., 2017; Griffiths et al., 2020; Montero-Odasso et al., 2020). We suggest here that a differential role of auditory fiber processing for specific imbalances in excitation/inhibition can be regarded as a key signature of hearing disorders with or without cognitive decline.

\section{AUTHOR CONTRIBUTIONS}

MK designed, wrote, and revised the manuscript. WS wrote the manuscript and made the figures. KS, GEH, LR, CB, and RL wrote and revised the manuscript. YLH wrote the figure legends and helped writing the manuscript. All authors contributed to the article and approved the submitted version.

\section{FUNDING}

This work was funded by the Deutsche Forschungsgemeinschaft (DFG, German Research Foundation) - Project number 335549539/GRK2381, FOR 2060 project RU 713/3-2 (WS and LR), SPP 1608 RU 316/12-1 (LR), KN 316/12-1 (MK). MK and LR are members of the Research Training Group [grant number 335549539/GRK 2381] "cGMP: From Bedside to Bench". This work was also supported by the Deutsche Forschungsgemeinschaft (Cluster of Excellence 2177 "Hearing4all" Project number 390895286) (RL and KS), EU-LACH Grant \#16/T01-0118 and "Computational Neuroimaging of the human Brainstem at 9.4 Tesla" (BMBF \#01GQ1805B) (GEH).

\section{ACKNOWLEDGMENTS}

English language services were provided by stels-ol.de.

regulate neurovascular coupling. Nature 585, 91-95. doi: 10.1038/s41586-0202589-x

Anenberg, E., Chan, A. W., Xie, Y., LeDue, J. M., and Murphy, T. H. (2015). Optogenetic stimulation of GABA neurons can decrease local neuronal activity while increasing cortical blood flow. J. Cereb. Blood Flow Metab. 35, 1579-1586. doi: $10.1038 / j \mathrm{cbfm} .2015 .140$

Ankmnal Veeranna, S., Allan, C., Macpherson, E., and Allen, P. (2019). Spectral ripple discrimination in children with auditory processing disorder. Int. J. Audiol. 58, 733-737. doi: 10.1080/14992027.2019.1627007

Arango-Lievano, M., Borie, A. M., Dromard, Y., Murat, M., Desarmenien, M. G., Garabedian, M. J., et al. (2019). Persistence of learning-induced synapses depends on neurotrophic priming of glucocorticoid receptors. Proc. Natl. Acad. Sci. U S A. 116, 13097-13106. doi: 10.1073/pnas.1903203116 
Attwell, D., Buchan, A. M., Charpak, S., Lauritzen, M., Macvicar, B. A., and Newman, E. A. (2010). Glial and neuronal control of brain blood flow. Nature 468, 232-243. doi: 10.1038/nature09613

Auerbach, B. D., Radziwon, K., and Salvi, R. (2019). Testing the Central Gain Model: Loudness Growth Correlates with Central Auditory Gain Enhancement in a Rodent Model of Hyperacusis. Neuroscience 407, 93-107. doi: 10.1016/j. neuroscience.2018.09.036

Auerbach, B. D., Rodrigues, P. V., and Salvi, R. J. (2014). Central gain control in tinnitus and hyperacusis. Front. Neurol. 5:206. doi: 10.3389/fneur.2014.00206

Awad, P. N., Amegandjin, C. A., Szczurkowska, J., Carrico, J. N., Fernandes, do Nascimento, A. S., et al. (2018). KCC2 Regulates Dendritic Spine Formation in a Brain-Region Specific and BDNF Dependent Manner. Cereb. Cortex 28, 4049-4062. doi: 10.1093/cercor/bhy198

Babola, T. A., Li, S., Gribizis, A., Lee, B. J., Issa, J. B., Wang, H. C., et al. (2018). Homeostatic Control of Spontaneous Activity in the Developing Auditory System. Neuron 99, 511-524e515. doi: 10.1016/j.neuron.2018.07.004

Bajo, V. M., Leach, N. D., Cordery, P. M., Nodal, F. R., and King, A. J. (2014). The cholinergic basal forebrain in the ferret and its inputs to the auditory cortex. Eur. J. Neurosci. 40, 2922-2940. doi: 10.1111/ejn.12653

Balakrishnan, V., Becker, M., Lohrke, S., Nothwang, H. G., Guresir, E., and Friauf, E. (2003). Expression and function of chloride transporters during development of inhibitory neurotransmission in the auditory brainstem. J. Neurosci. 23, 4134-4145. doi: 10.1523/JNEUROSCI.23-10-04134.2003

Bauer, C. A., Turner, J. G., Caspary, D. M., Myers, K. S., and Brozoski, T. J. (2008). Tinnitus and inferior colliculus activity in chinchillas related to three distinct patterns of cochlear trauma. J. Neurosci. Res. 86, 2564-2578. doi: 10.1002/jnr. 21699

Ben-Ari, Y. (2002). Excitatory actions of gaba during development: the nature of the nurture. Nat. Rev. Neurosci. 3, 728-739. doi: 10.1038/nrn920

Ben-Ari, Y., Cherubini, E., Corradetti, R., and Gaiarsa, J. L. (1989). Giant synaptic potentials in immature rat CA3 hippocampal neurones. J. Physiol. 416, 303-325. doi: 10.1113/jphysiol.1989.sp017762

Ben-Ari, Y., Khalilov, I., Kahle, K. T., and Cherubini, E. (2012). The GABA excitatory/inhibitory shift in brain maturation and neurological disorders. Neuroscientist 18, 467-486. doi: 10.1177/1073858412438697

Beukes, E. W., Manchaiah, V., Allen, P. M., Andersson, G., and Baguley, D. M. (2021). Exploring tinnitus heterogeneity. Prog. Brain Res. 260, 79-99. doi: 10. 1016/bs.pbr.2020.05.022

Bharadwaj, H. M., Masud, S., Mehraei, G., Verhulst, S., and Shinn-Cunningham, B. G. (2015). Individual differences reveal correlates of hidden hearing deficits. J. Neurosci. 35, 2161-2172. doi: 10.1523/JNEUROSCI.3915-14.2015

Blair, L. J., Criado-Marrero, M., Zheng, D., Wang, X., Kamath, S., Nordhues, B. A., et al. (2019). The Disease-Associated Chaperone FKBP51 Impairs Cognitive Function by Accelerating AMPA Receptor Recycling. eNeuro 6, ENEURO.242ENEURO.218. doi: 10.1523/ENEURO.0242-18.2019

Bledsoe, S. C. Jr., Nagase, S., Miller, J. M., and Altschuler, R. A. (1995). Deafnessinduced plasticity in the mature central auditory system. Neuroreport 7, 225 229. doi: 10.1097/00001756-199512290-00054

Bourien, J., Tang, Y., Batrel, C., Huet, A., Lenoir, M., Ladrech, S., et al. (2014). Contribution of auditory nerve fibers to compound action potential of the auditory nerve. J. Neurophysiol. 112, 1025-1039. doi: 10.1152/jn.00738.2013

Brigande, J. V., and Heller, S. (2009). Quo vadis, hair cell regeneration? Nat. Neurosci. 12, 679-685. doi: 10.1038/nn.2311

Butler, R., Bernier, P. M., Lefebvre, J., Gilbert, G., and Whittingstall, K. (2017). Decorrelated Input Dissociates Narrow Band gamma Power and BOLD in Human Visual Cortex. J. Neurosci. 37, 5408-5418. doi: 10.1523/JNEUROSCI. 3938-16.2017

Cai, R., Guo, F., Zhang, J., Xu, J., Cui, Y., and Sun, X. (2009). Environmental enrichment improves behavioral performance and auditory spatial representation of primary auditory cortical neurons in rat. Neurobiol. Learn. Mem. 91, 366-376. doi: 10.1016/j.nlm.2009.01.005

Cai, S., Ma, W. L., and Young, E. D. (2009). Encoding intensity in ventral cochlear nucleus following acoustic trauma: implications for loudness recruitment. J. Assoc. Res. Otolaryngol. 10, 5-22. doi: 10.1007/s10162-008-0142-y

Canlon, B., Theorell, T., and Hasson, D. (2013). Associations between stress and hearing problems in humans. Hearing Res. 295, 9-15. doi: 10.1016/j.heares. 2012.08.015
Caporarello, N., D’Angeli, F., Cambria, M. T., Candido, S., Giallongo, C., Salmeri, M., et al. (2019). Pericytes in Microvessels: From "Mural” Function to Brain and Retina Regeneration. Int. J. Mol. Sci. 20:6351. doi: 10.3390/ijms20246351

Caraiscos, V. B., Elliott, E. M., You-Ten, K. E., Cheng, V. Y., Belelli, D., Newell, J. G., et al. (2004). Tonic inhibition in mouse hippocampal CA1 pyramidal neurons is mediated by a5 subunit-containing gamma-aminobutyric acid type A receptors. Proc. Natl. Acad. Sci. USA 101, 3662-3667. doi: 10.1073/pnas. 0307231101

Cardin, J. A., Carlen, M., Meletis, K., Knoblich, U., Zhang, F., Deisseroth, K., et al. (2009). Driving fast-spiking cells induces gamma rhythm and controls sensory responses. Nature 459, 663-667. doi: 10.1038/nature08002

Caspary, D. M., Ling, L., Turner, J. G., and Hughes, L. F. (2008). Inhibitory neurotransmission, plasticity and aging in the mammalian central auditory system. J. Exp. Biol. 211, 1781-1791. doi: 10.1242/jeb.013581

Cauli, B., Tong, X. K., Rancillac, A., Serluca, N., Lambolez, B., Rossier, J., et al. (2004). Cortical GABA interneurons in neurovascular coupling: relays for subcortical vasoactive pathways. J. Neurosci. 24, 8940-8949. doi: 10.1523/ JNEUROSCI.3065-04.2004

Chacon-Fernandez, P., Sauberli, K., Colzani, M., Moreau, T., Ghevaert, C., and Barde, Y. A. (2016). Brain-derived Neurotrophic Factor in Megakaryocytes. J. Biol. Chem. 291, 9872-9881. doi: 10.1074/jbc.M116.720029

Chadha, N. K., Gordon, K. A., James, A. L., and Papsin, B. C. (2009). Tinnitus is prevalent in children with cochlear implants. Int. J. Pediatric Otorhinolaryngol. 73, 671-675. doi: 10.1016/j.ijporl.2008.12.032

Chen, G. D., and Jastreboff, P. J. (1995). Salicylate-induced abnormal activity in the inferior colliculus of rats. Hearing Res. 82, 158-178. doi: 10.1016/0378-5955(94) 00174-o

Chen, G., Zhang, Y., Li, X., Zhao, X., Ye, Q., Lin, Y., et al. (2017). Distinct Inhibitory Circuits Orchestrate Cortical beta and gamma Band Oscillations. Neuron 96, 1403-1418e1406. doi: 10.1016/j.neuron.2017.11.033

Cherubini, E., Griguoli, M., Safiulina, V., and Lagostena, L. (2011). The depolarizing action of GABA controls early network activity in the developing hippocampus. Mol. Neurobiol. 43, 97-106. doi: 10.1007/s12035-010-8147-z

Chow, B. W., Nunez, V., Kaplan, L., Granger, A. J., Bistrong, K., Zucker, H. L., et al. (2020). Caveolae in CNS arterioles mediate neurovascular coupling. Nature 579, 106-110. doi: 10.1038/s41586-020-2026-1

Chumak, T., Rüttiger, L., Lee, S. C., Campanelli, D., Zuccotti, A., Singer, W., et al. (2016). BDNF in Lower Brain Parts Modifies Auditory Fiber Activity to Gain Fidelity but Increases the Risk for Generation of Central Noise After Injury. Mol. Neurobiol. 53, 5607-5627. doi: 10.1007/s12035-015-9474-x

Collaborators, G. H. L. (2021). Hearing loss prevalence and years lived with disability, 1990-2019: findings from the Global Burden of Disease Study 2019. Lancet 397, 996-1009. doi: 10.1016/S0140-6736(21)00516-X

Colonnese, M. T., Phillips, M. A., Constantine-Paton, M., Kaila, K., and Jasanoff, A. (2008). Development of hemodynamic responses and functional connectivity in rat somatosensory cortex. Nat. Neurosci. 11, 72-79. doi: 10.1038/nn2017

Crönlein, T., Langguth, B., Pregler, M., Kreuzer, P. M., Wetter, T. C., and Schecklmann, M. (2016). Insomnia in patients with chronic tinnitus: Cognitive and emotional distress as moderator variables. J. Psychosom. Res. 83, 65-68. doi: 10.1016/j.jpsychores.2016.03.001

Crunelli, V., and Di Giovanni, G. (2014). Monoamine modulation of tonic GABAA inhibition. Rev. Neurosci. 25, 195-206. doi: 10.1515/revneuro-2013-0059

Csabai, D., Wiborg, O., and Czeh, B. (2018). Reduced Synapse and Axon Numbers in the Prefrontal Cortex of Rats Subjected to a Chronic Stress Model for Depression. Front. Cell. Neurosci. 12:24. doi: 10.3389/fncel.2018.00024

Cudmore, R. H., Dougherty, S. E., and Linden, D. J. (2017). Cerebral vascular structure in the motor cortex of adult mice is stable and is not altered by voluntary exercise. J. Cereb. Blood Flow Metab. 37, 3725-3743. doi: 10.1177/ 0271678X16682508

Cukier, H. N., Griswold, A. J., Hofmann, N. K., Gomez, L., Whitehead, P. L., Abramson, R. K., et al. (2020). Three Brothers With Autism Carry a StopGain Mutation in the HPA-Axis Gene NR3C2. Autism Res. 13, 523-531. doi: 10.1002/aur.2269

Czeh, B., Vardya, I., Varga, Z., Febbraro, F., Csabai, D., Martis, L. S., et al. (2018). Long-Term Stress Disrupts the Structural and Functional Integrity of GABAergic Neuronal Networks in the Medial Prefrontal Cortex of Rats. Front. Cell. Neurosci. 12:148. doi: 10.3389/fncel.2018.00148 
Czeh, B., Varga, Z. K., Henningsen, K., Kovacs, G. L., Miseta, A., and Wiborg, O. (2015). Chronic stress reduces the number of GABAergic interneurons in the adult rat hippocampus, dorsal-ventral and region-specific differences. Hippocampus 25, 393-405. doi: 10.1002/hipo.22382

Davis, G. W., and Bezprozvanny, I. (2001). Maintaining the stability of neural function: a homeostatic hypothesis. Annu. Rev. Physiol. 63, 847-869. doi: 10. 1146/annurev.physiol.63.1.847

de Kloet, E. R. (2014). From receptor balance to rational glucocorticoid therapy. Endocrinology 155, 2754-2769. doi: 10.1210/en.2014-1048

de Kloet, E. R., Claessens, S. E., and Kentrop, J. (2014). Context modulates outcome of perinatal glucocorticoid action in the brain. Front. Endocrinol. 5:100. doi: 10.3389/fendo. 2014.00100

de Kloet, E. R., de Kloet, S. F., de Kloet, C. S., and de Kloet, A. D. (2019). Topdown and bottom-up control of stress-coping. J. Neuroendocrinol. 31:e12675. doi: $10.1111 /$ jne. 12675

de Villers-Sidani, E., Chang, E. F., Bao, S., and Merzenich, M. M. (2007). Critical period window for spectral tuning defined in the primary auditory cortex (A1) in the rat. J. Neurosci. 27, 180-189. doi: 10.1523/JNEUROSCI.3227-06.2007

Dehmel, S., Pradhan, S., Koehler, S., Bledsoe, S., and Shore, S. (2012). Noise overexposure alters long-term somatosensory-auditory processing in the dorsal cochlear nucleus-possible basis for tinnitus-related hyperactivity? J. Neurosci. 32, 1660-1671. doi: 10.1523/JNEUROSCI.4608-11.2012

Deng, D., Masri, S., Yao, L., Ma, X., Cao, X., Yang, S., et al. (2020). Increasing endogenous activity of NMDARs on GABAergic neurons increases inhibition, alters sensory processing and prevents noise-induced tinnitus. Sci. Rep. 10:11969. doi: 10.1038/s41598-020-68652-5

Derkach, V. A., Oh, M. C., Guire, E. S., and Soderling, T. R. (2007). Regulatory mechanisms of AMPA receptors in synaptic plasticity. Nat. Rev. Neurosci. 8, 101-113. doi: 10.1038/nrn2055

Deroche, M. L., Culling, J. F., Chatterjee, M., and Limb, C. J. (2014). Roles of the target and masker fundamental frequencies in voice segregation. J. Acoust. Soc. Am. 136:1225. doi: 10.1121/1.4890649

Dieni, S., Matsumoto, T., Dekkers, M., Rauskolb, S., Ionescu, M. S., Deogracias, R., et al. (2012). BDNF and its pro-peptide are stored in presynaptic dense core vesicles in brain neurons. J. Cell Biol. 196, 775-788. doi: 10.1083/jcb.201201038

Dinstein, I., Heeger, D. J., Lorenzi, L., Minshew, N. J., Malach, R., and Behrmann, M. (2012). Unreliable evoked responses in autism. Neuron 75, 981-991. doi: 10.1016/j.neuron.2012.07.026

Donovan, M. J., Lin, M. I., Wiegn, P., Ringstedt, T., Kraemer, R., Hahn, R., et al. (2000). Brain derived neurotrophic factor is an endothelial cell survival factor required for intramyocardial vessel stabilization. Development 127, 4531-4540.

Duguid, I., Branco, T., London, M., Chadderton, P., and Hausser, M. (2012). Tonic inhibition enhances fidelity of sensory information transmission in the cerebellar cortex. J. Neurosci. 32, 11132-11143. doi: 10.1523/JNEUROSCI.046012.2012

Easwar, V., Yamazaki, H., Deighton, M., Papsin, B., and Gordon, K. (2017). Simultaneous bilateral cochlear implants: Developmental advances do not yet achieve normal cortical processing. Brain Behav. 7:e00638. doi: 10.1002/brb3. 638

Eckert, P., Marchetta, P., Manthey, M. K., Walter, M. H., Jovanovic, S., Savitska, D., et al. (2021). Deletion of BDNF in Pax2 Lineage-Derived Interneuron Precursors in the Hindbrain Hampers the Proportion of Excitation/Inhibition, Learning, and Behavior. Front. Mol. Neurosci. 14:642679. doi: 10.3389/fnmol. 2021.642679

Eggermont, J. J., and Kral, A. (2016). Somatic memory and gain increase as preconditions for tinnitus: Insights from congenital deafness. Hearing Res. 333, 37-48. doi: 10.1016/j.heares.2015.12.018

Eggermont, J. J., and Tass, P. A. (2015). Maladaptive neural synchrony in tinnitus: origin and restoration. Front. Neurol. 6:29. doi: 10.3389/fneur.2015.00029

Engelien, A., Huber, W., Silbersweig, D., Stern, E., Frith, C. D., Doring, W., et al. (2000). The neural correlates of 'deaf-hearing' in man: conscious sensory awareness enabled by attentional modulation. Brain J. Neurol. 123(Pt 3), 532545. doi: 10.1093/brain/123.3.532

Engl, E., Jolivet, R., Hall, C. N., and Attwell, D. (2017). Non-signalling energy use in the developing rat brain. J. Cereb. Blood Flow Metab. 37, 951-966. doi: $10.1177 / 0271678 X 16648710$

Espinoza, C., Guzman, S. J., Zhang, X., and Jonas, P. (2018). Parvalbumin(+) interneurons obey unique connectivity rules and establish a powerful lateral-inhibition microcircuit in dentate gyrus. Nat. Commun. 9:4605. doi: 10.1038/s41467-018-06899-3

Fatemi, S. H., Halt, A. R., Stary, J. M., Kanodia, R., Schulz, S. C., and Realmuto, G. R. (2002). Glutamic acid decarboxylase 65 and $67 \mathrm{kDa}$ proteins are reduced in autistic parietal and cerebellar cortices. Biol. Psychiatry 52, 805-810. doi: 10.1016/s0006-3223(02)01430-0

Fatemi, S. H., Reutiman, T. J., Folsom, T. D., and Thuras, P. D. (2009). GABA(A) receptor downregulation in brains of subjects with autism. J. Autism Dev. Disord. 39, 223-230. doi: 10.1007/s10803-008-0646-7

Fatemi, S. H., Reutiman, T. J., Folsom, T. D., Rooney, R. J., Patel, D. H., and Thuras, P. D. (2010). mRNA and protein levels for GABAAalpha4, alpha5, betal and GABABR1 receptors are altered in brains from subjects with autism. J. Autism Dev. Disord. 40, 743-750. doi: 10.1007/s10803-009-0924-z

Ferando, I., and Mody, I. (2015). In vitro gamma oscillations following partial and complete ablation of $\mathrm{d}$ subunit-containing $\mathrm{GABA}_{A}$ receptors from parvalbumin interneurons. Neuropharmacology 88, 91-98. doi: 10.1016/j.neuropharm.2014. 09.010

Fernandez-Klett, F., Offenhauser, N., Dirnagl, U., Priller, J., and Lindauer, U. (2010). Pericytes in capillaries are contractile in vivo, but arterioles mediate functional hyperemia in the mouse brain. Proc. Natl. Acad. Sci. U S A. 107, 22290-22295. doi: 10.1073/pnas.1011321108

Ferrini, F., and De Koninck, Y. (2013). Microglia control neuronal network excitability via BDNF signalling. Neural Plast. 2013:429815. doi: 10.1155/2013/ 429815

Fitch, R. H., Alexander, M. L., and Threlkeld, S. W. (2013). Early neural disruption and auditory processing outcomes in rodent models: implications for developmental language disability. Front. Syst. Neurosci. 7:58. doi: 10.3389/ fnsys.2013.00058

Fiumelli, H., Cancedda, L., and Poo, M. M. (2005). Modulation of GABAergic transmission by activity via postsynaptic Ca2+-dependent regulation of KCC2 function. Neuron 48, 773-786. doi: 10.1016/j.neuron.2005.10.025

Fortunato, S., Forli, F., Guglielmi, V., De Corso, E., Paludetti, G., Berrettini, S., et al. (2016). A review of new insights on the association between hearing loss and cognitive decline in ageing. Acta Otorhinolaryngol. Ital. 36, 155-166. doi: 10.14639/0392-100X-993

Foss-Feig, J. H., Schauder, K. B., Key, A. P., Wallace, M. T., and Stone, W. L. (2017). Audition-specific temporal processing deficits associated with language function in children with autism spectrum disorder. Autism Res. 10, 1845-1856. doi: $10.1002 /$ aur. 1820

Fotaki, V., Price, D. J., and Mason, J. O. (2008). Newly identified patterns of Pax2 expression in the developing mouse forebrain. BMC Dev. Biol. 8:79. doi: 10.1186/1471-213X-8-79

Fox, A. M., Reid, C. L., Anderson, M., Richardson, C., and Bishop, D. V. (2012). Maturation of rapid auditory temporal processing and subsequent nonword repetition performance in children. Dev. Sci. 15, 204-211. doi: 10.1111/j.14677687.2011.01117.x

Friauf, E., and Lohmann, C. (1999). Development of auditory brainstem circuitry. Activity-dependent and activity-independent processes. Cell Tissue Res. 297, 187-195. doi: 10.1007/s004410051346

Friauf, E., Rust, M. B., Schulenborg, T., and Hirtz, J. J. (2011). Chloride cotransporters, chloride homeostasis, and synaptic inhibition in the developing auditory system. Hearing Res. 279, 96-110. doi: 10.1016/j.heares.2011.05.012

Friebe, A., Voussen, B., and Groneberg, D. (2018). NO-GC in cells 'off the beaten track'. Nitric Oxide 77, 12-18. doi: 10.1016/j.niox.2018.03.020

Fröhlich, F. (2016). Network Neuroscience. Amsterdam: Elsevier.

Furman, A. C., Kujawa, S. G., and Liberman, M. C. (2013). Noise-induced cochlear neuropathy is selective for fibers with low spontaneous rates. J. Neurophysiol. 110, 577-586. doi: 10.1152/jn.00164.2013

Gao, Y., Manzoor, N., and Kaltenbach, J. A. (2016). Evidence of activity-dependent plasticity in the dorsal cochlear nucleus, in vivo, induced by brief sound exposure. Hearing Res. 341, 31-42. doi: 10.1016/j.heares.2016.07.011

Gerken, G. M. (1996). Central tinnitus and lateral inhibition: an auditory brainstem model. Hearing Res. 97, 75-83. doi: 10.1016/s0378-5955(96)80009-8

Gill, K. M., and Grace, A. A. (2014). The role of a5 $\mathrm{GABA}_{A}$ receptor agonists in the treatment of cognitive deficits in schizophrenia. Curr. Pharm. Des. 20, 5069-5076. doi: 10.1016/j.bbr.2014.02.013

Girouard, H., Park, L., Anrather, J., Zhou, P., and Iadecola, C. (2007). Cerebrovascular nitrosative stress mediates neurovascular and endothelial 
dysfunction induced by angiotensin II. Arterioscler. Thromb. Vasc. Biol. 27, 303-309. doi: 10.1161/01.ATV.0000253885.41509.25

Glowatzki, E., and Fuchs, P. A. (2000). Cholinergic synaptic inhibition of inner hair cells in the neonatal mammalian cochlea. Science 288, 2366-2368. doi: $10.1126 /$ science.288.5475.2366

Glowatzki, E., and Fuchs, P. A. (2002). Transmitter release at the hair cell ribbon synapse. Nat. Neurosci. 5, 147-154. doi: 10.1038/nn796

Goel, A., Cantu, D. A., Guilfoyle, J., Chaudhari, G. R., Newadkar, A., Todisco, B., et al. (2019). Author Correction: Impaired perceptual learning in a mouse model of Fragile X syndrome is mediated by parvalbumin neuron dysfunction and is reversible. Nat. Neurosci. 22:143. doi: 10.1038/s41593-018-0273-3

Goman, A. M., and Lin, F. R. (2016). Prevalence of Hearing Loss by Severity in the United States. Am. J. Public Health 106, 1820-1822. doi: 10.2105/AJPH.2016. 303299

Goyal, M. S., Hawrylycz, M., Miller, J. A., Snyder, A. Z., and Raichle, M. E. (2014). Aerobic glycolysis in the human brain is associated with development and neotenous gene expression. Cell Metabol. 19, 49-57. doi: 10.1016/j.cmet.2013. 11.020

Graham, C. E., and Vetter, D. E. (2011). The mouse cochlea expresses a local hypothalamic-pituitary-adrenal equivalent signaling system and requires corticotropin-releasing factor receptor 1 to establish normal hair cell innervation and cochlear sensitivity. J. Neurosci. 31, 1267-1278. doi: 10.1523/ JNEUROSCI.4545-10.2011

Grant, L., Yi, E., and Glowatzki, E. (2010). Two modes of release shape the postsynaptic response at the inner hair cell ribbon synapse. J. Neurosci. 30, 4210-4220. doi: 10.1523/JNEUROSCI.4439-09.2010

Griffen, T. C., and Maffei, A. (2014). GABAergic synapses: their plasticity and role in sensory cortex. Front. Cell. Neurosci. 8:91. doi: 10.3389/fncel.2014.00091

Griffiths, T. D., Lad, M., Kumar, S., Holmes, E., McMurray, B., Maguire, E. A., et al. (2020). How Can Hearing Loss Cause Dementia? Neuron 108, 401-412. doi: 10.1016/j.neuron.2020.08.003

Gu, J. W., Herrmann, B. S., Levine, R. A., and Melcher, J. R. (2012). Brainstem auditory evoked potentials suggest a role for the ventral cochlear nucleus in tinnitus. J. Assoc. Res. Otolaryngol. 13, 819-833. doi: 10.1007/s10162-0120344-1

Haigh, S. M., Coffman, B. A., Murphy, T. K., Butera, C. D., and Salisbury, D. F. (2016). Abnormal auditory pattern perception in schizophrenia. Schizophr. Res. 176, 473-479. doi: 10.1016/j.schres.2016.07.007

Hall, C. N., Reynell, C., Gesslein, B., Hamilton, N. B., Mishra, A., Sutherland, B. A., et al. (2014). Capillary pericytes regulate cerebral blood flow in health and disease. Nature 508, 55-60. doi: 10.1038/nature 13165

Hamalainen, J. A., Ortiz-Mantilla, S., and Benasich, A. A. (2011). Source localization of event-related potentials to pitch change mapped onto ageappropriate MRIs at 6 months of age. NeuroImage 54, 1910-1918. doi: 10.1016/ j.neuroimage.2010.10.016

Hamilton, L. S., Sohl-Dickstein, J., Huth, A. G., Carels, V. M., Deisseroth, K., and Bao, S. (2013). Optogenetic activation of an inhibitory network enhances feedforward functional connectivity in auditory cortex. Neuron 80, 1066-1076. doi: 10.1016/j.neuron.2013.08.017

Han, K., Lee, M., Lim, H. K., Jang, M. W., Kwon, J., Lee, C. J., et al. (2020). Excitation-Inhibition Imbalance Leads to Alteration of Neuronal Coherence and Neurovascular Coupling under Acute Stress. J. Neurosci. 40, 9148-9162. doi: 10.1523/JNEUROSCI.1553-20.2020

Han, K., Min, J., Lee, M., Kang, B. M., Park, T., Hahn, J., et al. (2019). Neurovascular Coupling under Chronic Stress Is Modified by Altered GABAergic Interneuron Activity. J. Neurosci. 39, 10081-10095. doi: 10.1523/JNEUROSCI.1357-19.2019

Heeringa, A. N., and van Dijk, P. (2014). The dissimilar time course of temporary threshold shifts and reduction of inhibition in the inferior colliculus following intense sound exposure. Hear. Res. 312, 38-47. doi: 10.1016/j.heares.2014.03. 004

Heil, P., Neubauer, H., Brown, M., and Irvine, D. R. (2008). Towards a unifying basis of auditory thresholds: distributions of the first-spike latencies of auditorynerve fibers. Hearing Res. 238, 25-38. doi: 10.1016/j.heares.2007.09.014

Heinz, M. G., and Young, E. D. (2004). Response growth with sound level in auditory-nerve fibers after noise-induced hearing loss. J. Neurophysiol. 91, 784-795. doi: 10.1152/jn.00776.2003

Heinz, M. G., Issa, J. B., and Young, E. D. (2005). Auditory-nerve rate responses are inconsistent with common hypotheses for the neural correlates of loudness recruitment. J. Assoc. Res. Otolaryngol. JARO 6, 91-105. doi: 10.1007/s10162004-5043-0

Hill, J. L., Hardy, N. F., Jimenez, D. V., Maynard, K. R., Kardian, A. S., Pollock, C. J., et al. (2016). Loss of promoter IV-driven BDNF expression impacts oscillatory activity during sleep, sensory information processing and fear regulation. Transl. Psychiatry 6:e873. doi: 10.1038/tp.2016.153

Hill, R. A., Tong, L., Yuan, P., Murikinati, S., Gupta, S., and Grutzendler, J. (2015). Regional Blood Flow in the Normal and Ischemic Brain Is Controlled by Arteriolar Smooth Muscle Cell Contractility and Not by Capillary Pericytes. Neuron 87, 95-110. doi: 10.1016/j.neuron.2015.06.001

Hirtz, J. J., Boesen, M., Braun, N., Deitmer, J. W., Kramer, F., Lohr, C., et al. (2011). Cav1.3 calcium channels are required for normal development of the auditory brainstem. J. Neurosci. 31, 8280-8294. doi: 10.1523/JNEUROSCI.5098-10.2011

Hofmeier, B., Wertz, J., Refat, F., Hinrichs, P., Saemisch, J., Singer, W., et al. (2021). Functional biomarkers that distinguish between tinnitus with and without hyperacusis. Clin. Transl. Med. 11:e378. doi: 10.1002/ctm2.378

Hofmeier, B., Wolpert, S., Aldamer, E. S., Walter, M., Thiericke, J., Braun, C., et al. (2018). Reduced sound-evoked and resting-state BOLD fMRI connectivity in tinnitus. NeuroImage Clin. 20, 637-649. doi: 10.1016/j.nicl.2018.08.029

Hong, E. J., McCord, A. E., and Greenberg, M. E. (2008). A biological function for the neuronal activity-dependent component of Bdnf transcription in the development of cortical inhibition. Neuron 60, 610-624. doi: 10.1016/j.neuron. 2008.09.024

Houtsma, A. J. M., and Smurzynski, J. (1990). Pitch identification and discrimination for complex tones with many harmonics. J. Acoust. Soc. Am. 87, 304-310.

Hsieh, T. H., Lee, H. H. C., Hameed, M. Q., Pascual-Leone, A., Hensch, T. K., and Rotenberg, A. (2017). Trajectory of Parvalbumin Cell Impairment and Loss of Cortical Inhibition in Traumatic Brain Injury. Cereb. Cortex 27, 5509-5524. doi: $10.1093 /$ cercor/bhw318

Hu, H., Gan, J., and Jonas, P. (2014). Interneurons. Fast-spiking, parvalbumin(+) GABAergic interneurons: from cellular design to microcircuit function. Science 345:1255263. doi: $10.1126 /$ science. 1255263

Hu, H., Roth, F. C., Vandael, D., and Jonas, P. (2018). Complementary Tuning of $\mathrm{Na}(+)$ and $\mathrm{K}(+)$ Channel Gating Underlies Fast and Energy-Efficient Action Potentials in GABAergic Interneuron Axons. Neuron 98, 156-165e156. doi: 10.1016/j.neuron.2018.02.024

Iadecola, C. (2017). The Neurovascular Unit Coming of Age: A Journey through Neurovascular Coupling in Health and Disease. Neuron 96, 17-42. doi: 10.1016/ j.neuron.2017.07.030

Ibrahim, B. A., and Llano, D. A. (2019). Aging and Central Auditory Disinhibition: Is It a Reflection of Homeostatic Downregulation or Metabolic Vulnerability? Brain Sci. 9:351. doi: 10.3390/brainsci9120351

Irvine, D. R. F. (2018a). Auditory perceptual learning and changes in the conceptualization of auditory cortex. Hearing Res. 366, 3-16. doi: 10.1016/j. heares.2018.03.011

Irvine, D. R. F. (2018b). Plasticity in the auditory system. Hearing Res. 362, 61-73. Itami, C., Kimura, F., and Nakamura, S. (2007). Brain-derived neurotrophic factor regulates the maturation of layer 4 fast-spiking cells after the second postnatal week in the developing barrel cortex. J. Neurosci. 27, 2241-2252. doi: 10.1523/ JNEUROSCI.3345-06.2007

Jafarpour, A., Griffin, S., Lin, J. J., and Knight, R. T. (2019). Medial Orbitofrontal Cortex, Dorsolateral Prefrontal Cortex, and Hippocampus Differentially Represent the Event Saliency. J. Cogn. Neurosci. 31, 874-884. doi: 10.1162/jocn_ a_01392

Ji, X. Y., Zingg, B., Mesik, L., Xiao, Z., Zhang, L. I., and Tao, H. W. (2016). Thalamocortical Innervation Pattern in Mouse Auditory and Visual Cortex: Laminar and Cell-Type Specificity. Cereb. Cortex 26, 2612-2625. doi: 10.1093/ cercor/bhv099

Johnson, J. C. S., Marshall, C. R., Weil, R. S., Bamiou, D. E., Hardy, C. J. D., and Warren, J. D. (2021). Hearing and dementia: from ears to brain. Brain J. Neurol. 144, 391-401. doi: 10.1093/brain/awaa429

Johnson, S. L., Eckrich, T., Kuhn, S., Zampini, V., Franz, C., Ranatunga, K. M., et al. (2011). Position-dependent patterning of spontaneous action potentials in immature cochlear inner hair cells. Nat. Neurosci. 14, 711-717. doi: 10.1038/nn. 2803

Johnson, S. L., Kuhn, S., Franz, C., Ingham, N., Furness, D. N., Knipper, M., et al. (2013). Presynaptic maturation in auditory hair cells requires a critical 
period of sensory-independent spiking activity. Proc. Natl. Acad. Sci. U S A. 110, 8720-8725. doi: 10.1073/pnas.1219578110

Kaernbach, C., and Bering, C. (2001). Exploring the temporal mechanism involved in the pitch of unresolved harmonics. J. Acoust. Soc. Am. 110, 1039-1048. doi: $10.1121 / 1.1381535$

Kalappa, B. I., Brozoski, T. J., Turner, J. G., and Caspary, D. M. (2014). Single unit hyperactivity and bursting in the auditory thalamus of awake rats directly correlates with behavioural evidence of tinnitus. J. Physiol. 592, 5065-5078. doi: 10.1113/jphysiol.2014.278572

Kandler, K., and Friauf, E. (1995). Development of glycinergic and glutamatergic synaptic transmission in the auditory brainstem of perinatal rats. J. Neurosci. 15, 6890-6904. doi: 10.1523/JNEUROSCI.15-10-06890.1995

Kandler, K., and Gillespie, D. C. (2005). Developmental refinement of inhibitory sound-localization circuits. Trends Neurosci. 28, 290-296. doi: 10.1016/j.tins. 2005.04.007

Kandler, K., Clause, A., and Noh, J. (2009). Tonotopic reorganization of developing auditory brainstem circuits. Nat. Neurosci. 12, 711-717. doi: 10.1038/nn. 2332

Khirug, S., Ahmad, F., Puskarjov, M., Afzalov, R., Kaila, K., and Blaesse, P. (2010). A single seizure episode leads to rapid functional activation of KCC2 in the neonatal rat hippocampus. J. Neurosci. 30, 12028-12035. doi: 10.1523/ JNEUROSCI.3154-10.2010

Kilgard, M. P., Pandya, P. K., Engineer, N. D., and Moucha, R. (2002). Cortical network reorganization guided by sensory input features. Biol. Cybernet. 87, 333-343. doi: 10.1007/s00422-002-0352-z

Kim, H., Ahrlund-Richter, S., Wang, X., Deisseroth, K., and Carlen, M. (2016). Prefrontal Parvalbumin Neurons in Control of Attention. Cell 164, 208-218. doi: 10.1016/j.cell.2015.11.038

Kimura, F., and Itami, C. (2019). A hypothetical model concerning how spike-timing-dependent plasticity contributes to neural circuit formation and initiation of the critical period in barrel cortex. J. Neurosci. 39, 3784-3791. doi: 10.1523/JNEUROSCI.1684-18.2019

Kisler, K., Nelson, A. R., Montagne, A., and Zlokovic, B. V. (2017). Cerebral blood flow regulation and neurovascular dysfunction in Alzheimer disease. Nat. Rev. Neurosci. 18, 419-434. doi: 10.1038/nrn.2017.48

Kitzes, L. M. (1984). Some physiological consequences of neonatal cochlear destruction in the inferior colliculus of the gerbil. Meriones Unguiculatus Brain Res. 306, 171-178. doi: 10.1016/0006-8993(84)90366-4

Kitzes, L. M., and Semple, M. N. (1985). Single-unit responses in the inferior colliculus: effects of neonatal unilateral cochlear ablation. J. Neurophysiol. 53 , 1483-1500. doi: 10.1152/jn.1985.53.6.1483

Knipper, M., Mazurek, B., van Dijk, P., and Schulz, H. (2021). Too blind to see the elephant? Why neuroscientists ought to be interested in tinnitus. JARO 22, 609-621. doi: 10.1007/s10162-021-00815-1

Knipper, M., Panford-Walsh, R., Singer, W., Rüttiger, L., and Zimmermann, U. (2015). Specific synaptopathies diversify brain responses and hearing disorders: you lose the gain from early life. Cell Tissue Res. 361, 77-93. doi: 10.1007/ s00441-015-2168-x

Knipper, M., Van Dijk, P., Nunes, I., Rüttiger, L., and Zimmermann, U. (2013). Advances in the neurobiology of hearing disorders: recent developments regarding the basis of tinnitus and hyperacusis. Prog. Neurobiol. 111, 17-33. doi: $10.1016 /$ j.pneurobio.2013.08.002

Knipper, M., van Dijk, P., Schulze, H., Mazurek, B., Krauss, P., Scheper, V., et al. (2020). The Neural Bases of Tinnitus: Lessons from Deafness and Cochlear Implants. J. Neurosci. 40, 7190-7202. doi: 10.1523/JNEUROSCI.1314- 19.2020

Kocharyan, A., Fernandes, P., Tong, X. K., Vaucher, E., and Hamel, E. (2008). Specific subtypes of cortical GABA interneurons contribute to the neurovascular coupling response to basal forebrain stimulation. J. Cereb. Blood Flow Metab. 28, 221-231. doi: 10.1038/sj.jcbfm. 9600558

Koehler, S. D., and Shore, S. E. (2013). Stimulus timing-dependent plasticity in dorsal cochlear nucleus is altered in tinnitus. J. Neurosci. 33, 19647-19656. doi: 10.1523/JNEUROSCI.2788-13.2013

Korb, E., and Finkbeiner, S. (2011). Arc in synaptic plasticity: from gene to behavior. Trends Neurosci. 34, 591-598. doi: 10.1016/j.tins.2011.08.007

Kotak, V. C., Fujisawa, S., Lee, F. A., Karthikeyan, O., Aoki, C., and Sanes, D. H. (2005). Hearing loss raises excitability in the auditory cortex. J. Neurosci. 25, 3908-3918. doi: 10.1523/JNEUROSCI.5169-04.2005
Kotak, V. C., Takesian, A. E., MacKenzie, P. C., and Sanes, D. H. (2013). Rescue of inhibitory synapse strength following developmental hearing loss. PLoS One 8:e53438. doi: 10.1371/journal.pone.0053438

Kozberg, M. G., Chen, B. R., DeLeo, S. E., Bouchard, M. B., and Hillman, E. M. (2013). Resolving the transition from negative to positive blood oxygen leveldependent responses in the developing brain. Proc. Natl. Acad. Sci. U S A. 110, 4380-4385. doi: 10.1073/pnas.1212785110

Kral, A., Dorman, M. F., and Wilson, B. S. (2019). Neuronal Development of Hearing and Language: Cochlear Implants and Critical Periods. Annu. Rev. Neurosci. 42, 47-65. doi: 10.1146/annurev-neuro-080317-061513

Kraus, N., and White-Schwoch, T. (2015). Unraveling the Biology of Auditory Learning: A Cognitive-Sensorimotor-Reward Framework. Trends Cognit. Sci. 19, 642-654. doi: 10.1016/j.tics.2015.08.017

Kujawa, S. G., and Liberman, M. C. (2009). Adding insult to injury: cochlear nerve degeneration after "temporary" noise-induced hearing loss. J. Neurosci. 29, 14077-14085. doi: 10.1523/JNEUROSCI.2845-09.2009

Kuwada, S., Anderson, J. S., Batra, R., Fitzpatrick, D. C., Teissier, N., and D’Angelo, W. R. (2002). Sources of the scalp-recorded amplitude-modulation following response. J. Am. Acad. Audiol. 13, 188-204.

Land, R., Baumhoff, P., Tillein, J., Lomber, S. G., Hubka, P., and Kral, A. (2016). Cross-Modal Plasticity in Higher-Order Auditory Cortex of Congenitally Deaf Cats Does Not Limit Auditory Responsiveness to Cochlear Implants. J. Neurosci. 36, 6175-6185. doi: 10.1523/JNEUROSCI.0046-16.2016

Landi, S., Ciucci, F., Maffei, L., Berardi, N., and Cenni, M. C. (2009). Setting the pace for retinal development: environmental enrichment acts through insulinlike growth factor 1 and brain-derived neurotrophic factor. J. Neurosci. 29, 10809-10819. doi: 10.1523/JNEUROSCI.1857-09.2009

Lazard, D. S., Giraud, A. L., Gnansia, D., Meyer, B., and Sterkers, O. (2012). Understanding the deafened brain: implications for cochlear implant rehabilitation. Eur. Ann. Otorhinolaryngol. Head Neck Dis. 129, 98-103. doi: 10.1016/j.anorl.2011.06.001

Ledo, A., Lourenco, C. F., Cadenas, E., Barbosa, R. M., and Laranjinha, J. (2021). The bioactivity of neuronal-derived nitric oxide in aging and neurodegeneration: Switching signaling to degeneration. Free Radic. Biol. Med. 162, 500-513. doi: 10.1016/j.freeradbiomed.2020.11.005

Lee, H. H., Deeb, T. Z., Walker, J. A., Davies, P. A., and Moss, S. J. (2011). NMDA receptor activity downregulates $\mathrm{KCC} 2$ resulting in depolarizing GABAA receptor-mediated currents. Nat. Neurosci. 14, 736-743. doi: 10.1038/nn.2806

Lee, L., Boorman, L., Glendenning, E., Christmas, C., Sharp, P., Redgrave, P., et al. (2020). Key Aspects of Neurovascular Control Mediated by Specific Populations of Inhibitory Cortical Interneurons. Cereb. Cortex 30, 2452-2464. doi: 10.1093/ cercor/bhz251

Lee, S. Y., Nam, D. W., Koo, J. W., De Ridder, D., Vanneste, S., and Song, J. J. (2017). No auditory experience, no tinnitus: Lessons from subjects with congenital- and acquired single-sided deafness. Hearing Res. 354, 9-15. doi: 10.1016/j.heares. 2017.08.002

Lee, S., Kang, B. M., Shin, M. K., Min, J., Heo, C., Lee, Y., et al. (2015). Chronic Stress Decreases Cerebrovascular Responses During Rat Hindlimb Electrical Stimulation. Front. Neurosci. 9:462. doi: 10.3389/fnins.2015.00462

Lehmann, K., Steinecke, A., and Bolz, J. (2012). GABA through the ages: regulation of cortical function and plasticity by inhibitory interneurons. Neural Plast. 2012:892784. doi: 10.1155/2012/892784

Lendahl, U., Nilsson, P., and Betsholtz, C. (2019). Emerging links between cerebrovascular and neurodegenerative diseases-a special role for pericytes. EMBO Rep. 20:e48070. doi: 10.15252/embr.201948070

Lendvai, B., Stern, E. A., Chen, B., and Svoboda, K. (2000). Experience-dependent plasticity of dendritic spines in the developing rat barrel cortex in vivo. Nature 404, 876-881. doi: 10.1038/35009107

Leutgeb, J. K., Leutgeb, S., Moser, M. B., and Moser, E. I. (2007). Pattern separation in the dentate gyrus and CA3 of the hippocampus. Science 315, 961-966. doi: $10.1126 /$ science. 1135801

Li, S., Kumar, T. P., Joshee, S., Kirschstein, T., Subburaju, S., Khalili, J. S., et al. (2018). Endothelial cell-derived GABA signaling modulates neuronal migration and postnatal behavior. Cell Res. 28, 221-248. doi: 10.1038/cr.2017.135

Liberman, M. C. (1980). Efferent synapses in the inner hair cell area of the cat cochlea: an electron microscopic study of serial sections. Hear. Res. 3, 189-204. doi: 10.1016/0378-5955(80)90046-5 
Liberman, M. C. (1982). Single-neuron labeling in the cat auditory nerve. Science 216, 1239-1241. doi: 10.1126/science.7079757

Liberman, M. C. (2017). Noise-induced and age-related hearing loss: new perspectives and potential therapies. F1000Research 6:927. doi: 10.12688/ f1000research.11310.1

Liberman, M. C., and Kujawa, S. G. (2017). Cochlear synaptopathy in acquired sensorineural hearing loss: Manifestations and mechanisms. Hearing Res. 349, 138-147. doi: 10.1016/j.heares.2017.01.003

Lin, F. R., Niparko, J. K., and Ferrucci, L. (2011). Hearing loss prevalence in the United States. Arch. Internal Med. 171, 1851-1852.

Lin, H. W., Furman, A. C., Kujawa, S. G., and Liberman, M. C. (2011). Primary neural degeneration in the Guinea pig cochlea after reversible noise-induced threshold shift. J. Assoc. Res. Otolaryngol. 12, 605-616. doi: 10.1007/s10162011-0277-0

Livingston, G., Sommerlad, A., Orgeta, V., Costafreda, S. G., Huntley, J., Ames, D., et al. (2017). Dementia prevention, intervention, and care. Lancet 390, 2673-2734.

Lohmann, C., and Friauf, E. (1996). Distribution of the calcium-binding proteins parvalbumin and calretinin in the auditory brainstem of adult and developing rats. J. Comparat. Neurol. 367, 90-109.

Lohrke, S., Srinivasan, G., Oberhofer, M., Doncheva, E., and Friauf, E. (2005). Shift from depolarizing to hyperpolarizing glycine action occurs at different perinatal ages in superior olivary complex nuclei. Eur. J. Neurosci. 22, 2708-2722. doi: $10.1111 /$ j.1460-9568.2005.04465.x

Lohse, M., Bajo, V. M., King, A. J., and Willmore, B. D. B. (2020). Neural circuits underlying auditory contrast gain control and their perceptual implications. Nat. Commun. 11:324. doi: 10.1038/s41467-019-14163-5

Lomber, S. G., Meredith, M. A., and Kral, A. (2010). Cross-modal plasticity in specific auditory cortices underlies visual compensations in the deaf. Nat. Neurosci. 13, 1421-1427. doi: 10.1038/nn.2653

Lourenco, C. F., Santos, R. M., Barbosa, R. M., Cadenas, E., Radi, R., and Laranjinha, J. (2014). Neurovascular coupling in hippocampus is mediated via diffusion by neuronal-derived nitric oxide. Free Radic. Biol. Med. 73, 421-429. doi: 10.1016/j.freeradbiomed.2014.05.021

Lu, J., Lobarinas, E., Deng, A., Goodey, R., Stolzberg, D., Salvi, R. J., et al. (2011). GABAergic neural activity involved in salicylate-induced auditory cortex gain enhancement. Neuroscience 189, 187-198. doi: 10.1016/j.neuroscience.2011.04. 073

Mallei, A., Baj, G., Ieraci, A., Corna, S., Musazzi, L., Lee, F. S., et al. (2015). Expression and Dendritic Trafficking of BDNF-6 Splice Variant are Impaired in Knock-In Mice Carrying Human BDNF Val66Met Polymorphism. Int. J. Neuropsychopharmacol. 18:yv069. doi: 10.1093/ijnp/pyv069

Malmierca, M. S., Sanchez-Vives, M. V., Escera, C., and Bendixen, A. (2014). Neuronal adaptation, novelty detection and regularity encoding in audition. Front. Syst. Neurosci. 8:111. doi: 10.3389/fnsys.2014.00111

Mamashli, F., Khan, S., Bharadwaj, H., Michmizos, K., Ganesan, S., Garel, K. A., et al. (2017). Auditory processing in noise is associated with complex patterns of disrupted functional connectivity in autism spectrum disorder. Autism Res. 10, 631-647. doi: 10.1002/aur.1714

Marchetta, P., Savitska, D., Kubler, A., Asola, G., Manthey, M., Mohrle, D., et al. (2020). Age-Dependent Auditory Processing Deficits after Cochlear Synaptopathy Depend on Auditory Nerve Latency and the Ability of the Brain to Recruit LTP/BDNF. Brain Sci. 10:710. doi: 10.3390/brainsci10100710

Maricich, S. M., and Herrup, K. (1999). Pax-2 expression defines a subset of GABAergic interneurons and their precursors in the developing murine cerebellum. J. Neurobiol. 41, 281-294.

Marin, O., and Rubenstein, J. L. (2001). A long, remarkable journey: tangential migration in the telencephalon. Nat. Rev. Neurosci. 2, 780-790. doi: 10.1038/ 35097509

Markram, H., Toledo-Rodriguez, M., Wang, Y., Gupta, A., Silberberg, G., and Wu, C. (2004). Interneurons of the neocortical inhibitory system. Nat. Rev. Neurosci. 5, 793-807. doi: 10.1038/nrn1519

Masri, S., Chan, N., Marsh, T., Zinsmaier, A., Schaub, D., Zhang, L., et al. (2021). Chemogenetic Activation of Cortical Parvalbumin-Positive Interneurons Reverses Noise-Induced Impairments in Gap Detection. J. Neurosci. 41, 88488857. doi: 10.1523/JNEUROSCI.2687-19.2021

Matt, L., Eckert, P., Panford-Walsh, R., Geisler, H. S., Bausch, A. E., Manthey, M., et al. (2018). Visualizing BDNF Transcript Usage During Sound-Induced
Memory Linked Plasticity. Front. Mol. Neurosci. 11:260. doi: 10.3389/fnmol. 2018.00260

McAlpine, D., Martin, R. L., Mossop, J. E., and Moore, D. R. (1997). Response properties of neurons in the inferior colliculus of the monaurally deafened ferret to acoustic stimulation of the intact ear. J. Neurophysiol. 78, 767-779. doi: $10.1152 /$ jn. 1997.78 .2 .767

McKlveen, J. M., Morano, R. L., Fitzgerald, M., Zoubovsky, S., Cassella, S. N., Scheimann, J. R., et al. (2016). Chronic Stress Increases Prefrontal Inhibition: A Mechanism for Stress-Induced Prefrontal Dysfunction. Biol. Psychiatry 80, 754-764. doi: 10.1016/j.biopsych.2016.03.2101

McKlveen, J. M., Myers, B., Flak, J. N., Bundzikova, J., Solomon, M. B., Seroogy, K. B., et al. (2013). Role of prefrontal cortex glucocorticoid receptors in stress and emotion. Biol. Psychiatry 74, 672-679. doi: 10.1016/j.biopsych.2013.03.024

Meddis, R. (2006). Auditory-nerve first-spike latency and auditory absolute threshold: a computer model. J. Acoust. Soc. Am. 119, 406-417.

Meltser, I., and Canlon, B. (2011). Protecting the auditory system with glucocorticoids. Hearing Res. 281, 47-55. doi: 10.1016/j.heares.2011.06.003

Meltser, I., Cederroth, C. R., Basinou, V., Savelyev, S., Lundkvist, G. S., and Canlon, B. (2014). TrkB-mediated protection against circadian sensitivity to noise trauma in the murine cochlea. Curr. Biol. CB 24, 658-663.

Merchan-Perez, A., and Liberman, M. C. (1996). Ultrastructural differences among afferent synapses on cochlear hair cells: correlations with spontaneous discharge rate. J. Comp. Neurol. 371, 208-221.

Milbrandt, J. C., Holder, T. M., Wilson, M. C., Salvi, R. J., and Caspary, D. M. (2000). GAD levels and muscimol binding in rat inferior colliculus following acoustic trauma. Hear. Res. 147, 251-260. doi: 10.1016/s0378-5955(00)00135-0

Miller, E. K., and Buschman, T. J. (2013). Cortical circuits for the control of attention. Curr. Opin. Neurobiol. 23, 216-222. doi: 10.1016/j.conb.2012.11.011

Mohn, J. L., Alexander, J., Pirone, A., Palka, C. D., Lee, S. Y., Mebane, L., et al. (2014). New molecular insights into cognitive and autistic-like disabilities. Mol. Psychiatry 19:1053. doi: 10.1038/mp.2014.129

Möhrle, D., Hofmeier, B., Amend, M., Wolpert, S., Ni, K., Bing, D., et al. (2019). Enhanced Central Neural Gain Compensates Acoustic Trauma-induced Cochlear Impairment, but Unlikely Correlates with Tinnitus and Hyperacusis. Neuroscience 407, 146-169. doi: 10.1016/j.neuroscience.2018.12.038

Möhrle, D., Ni, K., Varakina, K., Bing, D., Lee, S. C., Zimmermann, U., et al. (2016). Loss of auditory sensitivity from inner hair cell synaptopathy can be centrally compensated in the young but not old brain. Neurobiol. Aging 44, 173-184. doi: 10.1016/j.neurobiolaging.2016.05.001

Möhrle, D., Reimann, K., Wolter, S., Wolters, M., Varakina, K., Mergia, E., et al. (2017). NO-sensitive guanylate cyclase isoforms NO-GC1 and NO-GC2 contribute to noise-induced inner hair cell synaptopathy. Mol. Pharmacol. 92, 375-388. doi: 10.1124/mol.117.108548

Montero-Odasso, M., Ismail, Z., and Livingston, G. (2020). One third of dementia cases can be prevented within the next 25 years by tackling risk factors. The case "for" and "against". Alzheimers Res. Ther. 12:81. doi: 10.1186/s13195-02000646-x

Moore, D. R. (1994). Auditory brainstem of the ferret: long survival following cochlear removal progressively changes projections from the cochlear nucleus to the inferior colliculus. J. Comparat. Neurol. 339, 301-310. doi: 10.1002/cne. 903390209

Mossop, J. E., Wilson, M. J., Caspary, D. M., and Moore, D. R. (2000). Downregulation of inhibition following unilateral deafening. Hearing Res. 147, 183-187. doi: 10.1016/s0378-5955(00)00054-x

Mowery, T. M., Caras, M. L., Hassan, S. I., Wang, D. J., Dimidschstein, J., Fishell, G., et al. (2019). Preserving Inhibition during Developmental Hearing Loss Rescues Auditory Learning and Perception. J. Neurosci. 39, 8347-8361. doi: 10.1523/JNEUROSCI.0749-19.2019

Nadol, J. B. Jr. (1988). Innervation densities of inner and outer hair cells of the human organ of Corti. Evidence for auditory neural degeneration in a case of Usher's syndrome. ORL J. Oto-rhino-laryngol. Related Specialties 50, 363-370. doi: $10.1159 / 000276014$

Nardou, R., Yamamoto, S., Chazal, G., Bhar, A., Ferrand, N., Dulac, O., et al. (2011). Neuronal chloride accumulation and excitatory GABA underlie aggravation of neonatal epileptiform activities by phenobarbital. Brain J. Neurol. 134, 987-1002. doi: 10.1093/brain/awr041

Nehlig, A., Pereira, de Vasconcelos, A., and Boyet, S. (1989). Postnatal changes in local cerebral blood flow measured by the quantitative autoradiographic 
[14C]iodoantipyrine technique in freely moving rats. J. Cereb. Blood Flow Metab. 9, 579-588. doi: 10.1038/jcbfm. 1989.83

Neville, H., and Bavelier, D. (2002). Human brain plasticity: evidence from sensory deprivation and altered language experience. Prog. Brain Res. 138, 177-188. doi: 10.1016/S0079-6123(02)38078-6

Nordeen, K. W., Killackey, H. P., and Kitzes, L. M. (1983). Ascending projections to the inferior colliculus following unilateral cochlear ablation in the neonatal gerbil, Meriones unguiculatus. J. Comparat. Neurol. 214, 144-153. doi: 10.1002/ cne.902140204

Norena, A. J. (2011). An integrative model of tinnitus based on a central gain controlling neural sensitivity. Neurosci. Biobehav. Rev. 35, 1089-1109. doi: 10. 1016/j.neubiorev.2010.11.003

Norena, A. J., and Farley, B. J. (2013). Tinnitus-related neural activity: theories of generation, propagation, and centralization. Hearing Res. 295, 161-171. doi: 10.1016/j.heares.2012.09.010

Nornes, H. O., Dressler, G. R., Knapik, E. W., Deutsch, U., and Gruss, P. (1990). Spatially and temporally restricted expression of Pax 2 during murine neurogenesis. Development 109, 797-809.

Obleser, J., Wise, R. J., Dresner, M. A., and Scott, S. K. (2007). Functional integration across brain regions improves speech perception under adverse listening conditions. J. Neurosci. 27, 2283-2289. doi: 10.1523/JNEUROSCI. 4663-06.2007

Oleskevich, S., and Walmsley, B. (2002). Synaptic transmission in the auditory brainstem of normal and congenitally deaf mice. J. Physiol. 540, 447-455. doi: 10.1113/jphysiol.2001.013821

Ortiz-Mantilla, S., Hamalainen, J. A., Realpe-Bonilla, T., and Benasich, A. A. (2016). Oscillatory Dynamics Underlying Perceptual Narrowing of Native Phoneme Mapping from 6 to 12 Months of Age. J. Neurosci. 36, 12095-12105. doi: 10.1523/JNEUROSCI.1162-16.2016

Ortmann, M., Muller, N., Schlee, W., and Weisz, N. (2011). Rapid increases of gamma power in the auditory cortex following noise trauma in humans. Eur. J. Neurosci. 33, 568-575. doi: 10.1111/j.1460-9568.2010.07542.x

Ostrovskaya, O. I., Cao, G., Eroglu, C., and Harris, K. M. (2020). Developmental onset of enduring long-term potentiation in mouse hippocampus. Hippocampus 30, 1298-1312. doi: 10.1002/hipo.23257

Ouda, L., Profant, O., and Syka, J. (2015). Age-related changes in the central auditory system. Cell Tissue Res. 361, 337-358.

Oxenham, A. J. (2018). How We Hear: The Perception and Neural Coding of Sound. Annu. Rev. Psychol. 69, 27-50. doi: 10.1146/annurev-psych-122216011635

Pal, I., Paltati, C. R. B., Kaur, C., Shubhi, S., Kumar, P., Jacob, T. G., et al. (2019). Morphological and neurochemical changes in GABAergic neurons of the aging human inferior colliculus. Hearing Res. 377, 318-329. doi: 10.1016/j.heares. 2019.02.005

Parkhurst, C. N., Yang, G., Ninan, I., Savas, J. N., Yates, J. R. III, Lafaille, J. J., et al. (2013). Microglia promote learning-dependent synapse formation through brain-derived neurotrophic factor. Cell 155, 1596-1609. doi: 10.1016/j.cell.2013. 11.030

Pennington, J. R., and David, S. V. (2020). Complementary Effects of Adaptation and Gain Control on Sound Encoding in Primary Auditory Cortex. eNeuro 7, ENEURO.205-ENEURO.220. doi: 10.1523/ENEURO.0205-20.2020

Penrod, R. D., Kumar, J., Smith, L. N., McCalley, D., Nentwig, T. B., Hughes, B. W., et al. (2019). Activity-regulated cytoskeleton-associated protein (Arc/Arg3.1) regulates anxiety- and novelty-related behaviors. Genes Brain Behav. 18:e12561. doi: $10.1111 / \mathrm{gbb} .12561$

Petersen, B., Gjedde, A., Wallentin, M., and Vuust, P. (2013). Cortical plasticity after cochlear implantation. Neural Plastic. 2013:318521.

Petersen, B., Weed, E., Sandmann, P., Brattico, E., Hansen, M., Sorensen, S. D., et al. (2015). Brain responses to musical feature changes in adolescent cochlear implant users. Front. Hum. Neurosci. 9:7. doi: 10.3389/fnhum.2015.00007

Peterson, N., and Bergeson, T. R. (2015). Contribution of hearing aids to music perception by cochlear implant users. Cochlear Implants Int. 16(Suppl. 3), S71-S78. doi: 10.1179/1467010015Z.000000000268

Pi, H. J., Hangya, B., Kvitsiani, D., Sanders, J. I., Huang, Z. J., and Kepecs, A. (2013). Cortical interneurons that specialize in disinhibitory control. Nature 503, 521-524. doi: 10.1038/nature12676

Pirone, A., Alexander, J. M., Koenig, J. B., Cook-Snyder, D. R., Palnati, M., Wickham, R. J., et al. (2018). Social Stimulus Causes Aberrant Activation of the Medial Prefrontal Cortex in a Mouse Model With Autism-Like Behaviors. Front. Synaptic Neurosci. 10:35. doi: 10.3389/fnsyn.2018.00035

Plack, C. J., Barker, D., and Prendergast, G. (2014). Perceptual consequences of "hidden" hearing loss. Trends Hear. 18:2331216514550621.

Ponton, C. W., and Eggermont, J. J. (2001). Of kittens and kids: altered cortical maturation following profound deafness and cochlear implant use. Audiol. Neuro-otol. 6, 363-380. doi: 10.1159/000046846

Popelar, J., Erre, J. P., Aran, J. M., and Cazals, Y. (1994). Plastic changes in ipsi-contralateral differences of auditory cortex and inferior colliculus evoked potentials after injury to one ear in the adult guinea pig. Hear. Res. 72, 125-134. doi: 10.1016/0378-5955(94)90212-7

Potashner, S. J., Suneja, S. K., and Benson, C. G. (1997). Regulation of D-aspartate release and uptake in adult brain stem auditory nuclei after unilateral middle ear ossicle removal and cochlear ablation. Exp. Neurol. 148, 222-235. doi: 10.1006/exnr.1997.6641

Potashner, S. J., Suneja, S. K., and Benson, C. G. (2000). Altered glycinergic synaptic activities in guinea pig brain stem auditory nuclei after unilateral cochlear ablation. Hear. Res. 147, 125-136. doi: 10.1016/s0378-5955(00)00126-x

Pouille, F., and Scanziani, M. (2001). Enforcement of temporal fidelity in pyramidal cells by somatic feed-forward inhibition. Science 293, 1159-1163. doi: 10.1126/ science. 1060342

Rabinowitz, N. C., Willmore, B. D., Schnupp, J. W., and King, A. J. (2012). Spectrotemporal contrast kernels for neurons in primary auditory cortex. J. Neurosci. 32, 11271-11284. doi: 10.1523/JNEUROSCI.1715-12.2012

Recanzone, G. (2018). The effects of aging on auditory cortical function. Hear. Res. 366, 99-105. doi: 10.1016/j.heares.2018.05.013

Refat, F., Wertz, J., Hinrichs, P., Klose, U., Samy, H., Abdelkader, R. M., et al. (2021). Co-occurrence of Hyperacusis Accelerates With Tinnitus Burden Over Time and Requires Medical Care. Front. Neurol. 12:627522. doi: 10.3389/fneur. 2021.627522

Reynell, C., and Harris, J. J. (2013). The BOLD signal and neurovascular coupling in autism. Dev. Cognit. Neurosci. 6, 72-79. doi: 10.1016/j.dcn.2013.0 7.003

Rivera, C., Voipio, J., Payne, J. A., Ruusuvuori, E., Lahtinen, H., Lamsa, K., et al. (1999). The $\mathrm{K}+/ \mathrm{Cl}$ - co-transporter KCC2 renders GABA hyperpolarizing during neuronal maturation. Nature 397, 251-255. doi: 10.1038/16697

Roberts, L. E. (2018). Neural plasticity and its initiating conditions in tinnitus. HNO 66, 172-178. doi: 10.1007/s00106-017-0449-2

Roberts, L. E., and Salvi, R. (2019). Overview: Hearing loss, tinnitus, hyperacusis, and the role of central gain. Neuroscience 407, 1-7. doi: 10.1016/j.neuroscience. 2019.03.021

Rogalla, M. M., and Hildebrandt, K. J. (2020). Aging But Not Age-Related Hearing Loss Dominates the Decrease of Parvalbumin Immunoreactivity in the Primary Auditory Cortex of Mice. eNeuro 7, ENEURO.511-ENEURO.519. doi: 10.1523/ ENEURO.0511-19.2020

Rossignol, E., Kruglikov, I., van den Maagdenberg, A. M., Rudy, B., and Fishell, G. (2013). CaV 2.1 ablation in cortical interneurons selectively impairs fastspiking basket cells and causes generalized seizures. Ann. Neurol. 74, 209-222. doi: 10.1002/ana.23913

Roth, R. H., Cudmore, R. H., Tan, H. L., Hong, I., Zhang, Y., and Huganir, R. L. (2020). Cortical Synaptic AMPA Receptor Plasticity during Motor Learning. Neuron 105, 895-908e895. doi: 10.1016/j.neuron.2019.12.005

Rowitch, D. H., Kispert, A., and McMahon, A. P. (1999). Pax-2 regulatory sequences that direct transgene expression in the developing neural plate and external granule cell layer of the cerebellum. Brain Res. Dev. Brain Res. 117, 99-108. doi: 10.1016/s0165-3806(99)00104-2

Ruel, J., Chabbert, C., Nouvian, R., Bendris, R., Eybalin, M., Leger, C. L., et al. (2008). Salicylate enables cochlear arachidonic-acid-sensitive NMDA receptor responses. J. Neurosci. 28, 7313-7323. doi: 10.1523/JNEUROSCI.533507.V2008

Ruel, J., Wang, J., Dememes, D., Gobaille, S., Puel, J. L., and Rebillard, G. (2006). Dopamine transporter is essential for the maintenance of spontaneous activity of auditory nerve neurones and their responsiveness to sound stimulation. J. Neurochem. 97, 190-200. doi: 10.1111/j.1471-4159.2006.03722.x

Rüttiger, L., Singer, W., Panford-Walsh, R., Matsumoto, M., Lee, S. C., Zuccotti, A., et al. (2013). The reduced cochlear output and the failure to adapt the central auditory response causes tinnitus in noise exposed rats. PLoS One 8:e57247. doi: 10.1371/journal.pone.0057247 
Sachs, M. B., and Abbas, P. J. (1974). Rate versus level functions for auditorynerve fibers in cats: tone-burst stimuli. J. Acoust. Soc. Am. 56, 1835-1847. doi: 10.1121/1.1903521

Sakata, K., Jin, L., and Jha, S. (2010). Lack of promoter IV-driven BDNF transcription results in depression-like behavior. Genes Brain Behav. 9, 712-721. doi: 10.1111/j.1601-183X.2010.00605.x

Salvi, R. J., Wang, J., and Ding, D. (2000). Auditory plasticity and hyperactivity following cochlear damage. Hear. Res. 147, 261-274. doi: 10.1016/s03785955(00)00136-2

Sanes, D. H., Song, J., and Tyson, J. (1992). Refinement of dendritic arbors along the tonotopic axis of the gerbil lateral superior olive. Brain Res. Dev. Brain Res. 67, 47-55. doi: 10.1016/0165-3806(92)90024-q

Schaette, R., and Kempter, R. (2006). Development of tinnitus-related neuronal hyperactivity through homeostatic plasticity after hearing loss: a computational model. Eur. J. Neurosci. 23, 3124-3138. doi: 10.1111/j.1460-9568.2006.04774.x

Schaette, R., and Kempter, R. (2009). Predicting tinnitus pitch from patients' audiograms with a computational model for the development of neuronal hyperactivity. J. Neurophysiol. 101, 3042-3052. doi: 10.1152/jn.91256.2008

Schaette, R., and Kempter, R. (2012). Computational models of neurophysiological correlates of tinnitus. Front. Syst. Neurosci. 6:34. doi: 10.3389/fnsys.2012.00034

Schaette, R., and McAlpine, D. (2011). Tinnitus with a normal audiogram: physiological evidence for hidden hearing loss and computational model. J. Neurosci. 31, 13452-13457. doi: 10.1523/JNEUROSCI.2156-11.2011

Schonwiesner, M., Novitski, N., Pakarinen, S., Carlson, S., Tervaniemi, M., and Naatanen, R. (2007). Heschl's gyrus, posterior superior temporal gyrus, and mid-ventrolateral prefrontal cortex have different roles in the detection of acoustic changes. J. Neurophysiol. 97, 2075-2082. doi: 10.1152/jn.01083.2006

Schur, R. R., Draisma, L. W., Wijnen, J. P., Boks, M. P., Koevoets, M. G., Joels, M., et al. (2016). Brain GABA levels across psychiatric disorders: A systematic literature review and meta-analysis of (1) H-MRS studies. Hum. Brain Mapp. 37, 3337-3352. doi: 10.1002/hbm.23244

Seal, R. P., Akil, O., Yi, E., Weber, C. M., Grant, L., Yoo, J., et al. (2008). Sensorineural deafness and seizures in mice lacking vesicular glutamate transporter 3. Neuron 57, 263-275. doi: 10.1016/j.neuron.2007.11.032

Sedley, W. (2019). Tinnitus: Does gain explain? Neuroscience 407, 213-228. doi: 10.1016/j.neuroscience.2019.01.027

Sedley, W., Friston, K. J., Gander, P. E., Kumar, S., and Griffiths, T. D. (2016). An Integrative Tinnitus Model Based on Sensory Precision. Trends Neurosci. 39, 799-812. doi: 10.1016/j.tins.2016.10.004

Sergeyenko, Y., Lall, K., Liberman, M. C., and Kujawa, S. G. (2013). Agerelated cochlear synaptopathy: an early-onset contributor to auditory functional decline. J. Neurosci. 33, 13686-13694. doi: 10.1523/JNEUROSCI.1783-13.2013

Sharma, A., Dorman, M. F., and Kral, A. (2005a). The influence of a sensitive period on central auditory development in children with unilateral and bilateral cochlear implants. Hear. Res. 203, 134-143. doi: 10.1016/j.heares.2004.12.010

Sharma, A., Dorman, M. F., and Spahr, A. J. (2002). A sensitive period for the development of the central auditory system in children with cochlear implants: implications for age of implantation. Ear Hear. 23, 532-539. doi: 10.1097/ 00003446-200212000-00004

Sharma, A., Martin, K., Roland, P., Bauer, P., Sweeney, M. H., Gilley, P., et al. (2005b). P1 latency as a biomarker for central auditory development in children with hearing impairment. J. Am. Acad. Audiol. 16, 564-573. doi: 10.3766/jaaa. 16.8 .5

Sharma, M., Bist, S. S., and Kumar, S. (2016). Age-Related Maturation of Wave V Latency of Auditory Brainstem Response in Children. J. Audiol. Otol. 20, 97-101. doi: 10.7874/jao.2016.20.2.97

Shibata, S., Kakazu, Y., Okabe, A., Fukuda, A., and Nabekura, J. (2004). Experiencedependent changes in intracellular $\mathrm{Cl}$ - regulation in developing auditory neurons. Neurosci. Res. 48, 211-220. doi: 10.1016/j.neures.2003.10.011

Shore, S. E., Roberts, L. E., and Langguth, B. (2016). Maladaptive plasticity in tinnitus-triggers, mechanisms and treatment. Nat. Rev. Neurol. 12, 150-160. doi: 10.1038/nrneurol.2016.12

Shrestha, B. R., Chia, C., Wu, L., Kujawa, S. G., Liberman, M. C., and Goodrich, L. V. (2018). Sensory Neuron Diversity in the Inner Ear Is Shaped by Activity. Cell 174, 1229-1246e1217. doi: 10.1016/j.cell.2018.07.007

Sinclair, J. R., Jacobs, A. L., and Nirenberg, S. (2004). Selective ablation of a class of amacrine cells alters spatial processing in the retina. J. Neurosci. 24, 1459-1467. doi: 10.1523/JNEUROSCI.3959-03.2004
Singer, W., Kasini, K., Manthey, M., Eckert, P., Armbruster, P., Vogt, M. A., et al. (2018a). The glucocorticoid antagonist mifepristone attenuates sound-induced long-term deficits in auditory nerve response and central auditory processing in female rats. FASEB J. 32, 3005-3019. doi: 10.1096/fj.201701041RRR

Singer, W., Manthey, M., Panford-Walsh, R., Matt, L., Geisler, H. S., Passeri, E., et al. (2018b). BDNF-Live-Exon-Visualization (BLEV) Allows Differential Detection of BDNF Transcripts in vitro and in vivo. Front. Mol. Neurosci. 11:325. doi: 10.3389/fnmol.2018.00325

Singer, W., Panford-Walsh, R., and Knipper, M. (2014). The function of BDNF in the adult auditory system. Neuropharmacology 76(Pt C), 719-728. doi: 10.1016/ j.neuropharm.2013.05.008

Singer, W., Zuccotti, A., Jaumann, M., Lee, S. C., Panford-Walsh, R., Xiong, H., et al. (2013). Noise-induced inner hair cell ribbon loss disturbs central arc mobilization: a novel molecular paradigm for understanding tinnitus. Mol. Neurobiol. 47, 261-279. doi: 10.1007/s12035-012-8372-8

Slugocki, C., and Trainor, L. J. (2014). Cortical indices of sound localization mature monotonically in early infancy. Eur. J. Neurosci. 40, 3608-3619. doi: 10.1111/ ejn. 12741

Sohal, V. S., Zhang, F., Yizhar, O., and Deisseroth, K. (2009). Parvalbumin neurons and gamma rhythms enhance cortical circuit performance. Nature 459, 698702. doi: 10.1038/nature07991

Song, L., McGee, J. A., and Walsh, E. J. (2006). Consequences of combined maternal, fetal and persistent postnatal hypothyroidism on the development of auditory function in Tshrhyt mutant mice. Brain Res. 1101, 59-72. doi: 10.1016/j.brainres.2006.05.027

Sowell, E. R., Delis, D., Stiles, J., and Jernigan, T. L. (2001). Improved memory functioning and frontal lobe maturation between childhood and adolescence: a structural MRI study. J. Int. Neuropsychol. Soc. JINS 7, 312-322. doi: 10.1017/ s135561770173305x

Spoendlin, H. (1969). Innervation patterns in the organ of corti of the cat. Acta Otolaryngol. 67, 239-254. doi: 10.3109/00016486909125448

Stroganova, T. A., Komarov, K. S., Sysoeva, O. V., Goiaeva, D. E., Obukhova, T. S., Ovsiannikova, T. M., et al. (2020). Left hemispheric deficit in the sustained neuromagnetic response to periodic click trains in children with ASD. Mol. Autism 11:100. doi: 10.1186/s13229-020-00408-4

Sullivan, R. M., and Gratton, A. (2002). Prefrontal cortical regulation of hypothalamic-pituitary-adrenal function in the rat and implications for psychopathology: side matters. Psychoneuroendocrinology 27, 99-114. doi: 10. 1016/s0306-4530(01)00038-5

Sun, S., Babola, T., Pregernig, G., So, K. S., Nguyen, M., Su, S. M., et al. (2018). Hair Cell Mechanotransduction Regulates Spontaneous Activity and Spiral Ganglion Subtype Specification in the Auditory System. Cell 174, 1247-1263e1215. doi: 10.1016/j.cell.2018.07.008

Suneja, S. K., Benson, C. G., and Potashner, S. J. (1998). Glycine receptors in adult guinea pig brain stem auditory nuclei: regulation after unilateral cochlear ablation. Exp. Neurol. 154, 473-488. doi: 10.1006/exnr.1998.6946

Sweeney-Reed, C. M., Lee, H., Rampp, S., Zaehle, T., Buentjen, L., Voges, J., et al. (2016). Thalamic interictal epileptiform discharges in deep brain stimulated epilepsy patients. J. Neurol. 263, 2120-2126. doi: 10.1007/s00415-016-8246-5

Takano, T., and Matsui, K. (2015). Increased expression of GAP43 in interneurons in a rat model of experimental polymicrogyria. J. Child Neurol. 30, 716-728. doi: $10.1177 / 0883073814541476$

Takesian, A. E., Bogart, L. J., Lichtman, J. W., and Hensch, T. K. (2018). Inhibitory circuit gating of auditory critical-period plasticity. Nat. Neurosci. 21, 218-227. doi: 10.1038/s41593-017-0064-2

Thompson, A. C., Irvine, D. R. F., and Fallon, J. B. (2021). Provision of interaural time difference information in chronic intracochlear electrical stimulation enhances neural sensitivity to these differences in neonatally deafened cats. Hear. Res. 406:108253. doi: 10.1016/j.heares.2021.108253

Tighilet, B., Dutheil, S., Siponen, M. I., and Norena, A. J. (2016). Reactive Neurogenesis and Down-Regulation of the Potassium-Chloride Cotransporter KCC2 in the Cochlear Nuclei after Cochlear Deafferentation. Front. Pharmacol. 7:281. doi: 10.3389/fphar.2016.00281

Timmusk, T., Palm, K., Metsis, M., Reintam, T., Paalme, V., Saarma, M., et al. (1993). Multiple promoters direct tissue-specific expression of the rat BDNF gene. Neuron 10, 475-489. doi: 10.1016/0896-6273(93)90335-o

Tuvikene, J., Pruunsild, P., Orav, E., Esvald, E. E., and Timmusk, T. (2016). AP1 Transcription Factors Mediate BDNF-Positive Feedback Loop in Cortical 
Neurons. J. Neurosci. 36, 1290-1305. doi: 10.1523/JNEUROSCI.3360-15. 2016

Uchida, Y., Sugiura, S., Nishita, Y., Saji, N., Sone, M., and Ueda, H. (2019). Age-related hearing loss and cognitive decline - The potential mechanisms linking the two. Auris Nasus Larynx 46, 1-9. doi: 10.1016/j.anl.2018. 08.010

Uhlirova, H., Kilic, K., Tian, P., Thunemann, M., Desjardins, M., Saisan, P. A., et al. (2016). Cell type specificity of neurovascular coupling in cerebral cortex. eLife 5:e14315. doi: 10.7554/eLife.14315

Utevsky, A. V., and Platt, M. L. (2014). Status and the brain. PLoS Biol. 12:e1001941. doi: 10.1371/journal.pbio.1001941

Vaghi, V., Polacchini, A., Baj, G., Pinheiro, V. L., Vicario, A., and Tongiorgi, E. (2014). Pharmacological profile of brain-derived neurotrophic factor (BDNF) splice variant translation using a novel drug screening assay: a “quantitative code". J. Biol. Chem. 289, 27702-27713. doi: 10.1074/jbc.M114.58 6719

Van de Heyning, P., Vermeire, K., Diebl, M., Nopp, P., Anderson, I., and De Ridder, D. (2008). Incapacitating unilateral tinnitus in single-sided deafness treated by cochlear implantation. Ann. Otol. Rhinol. Laryngol. 117, 645-652. doi: 10.1177/000348940811700903

Vanneste, S., Joos, K., Ost, J., and De Ridder, D. (2018). Influencing connectivity and cross-frequency coupling by real-time source localized neurofeedback of the posterior cingulate cortex reduces tinnitus related distress. Neurobiol. Stress 8, 211-224. doi: 10.1016/j.ynstr.2016.11.003

Vazquez, A. L., Fukuda, M., and Kim, S. G. (2018). Inhibitory Neuron Activity Contributions to Hemodynamic Responses and Metabolic Load Examined Using an Inhibitory Optogenetic Mouse Model. Cereb. Cortex 28, 4105-4119. doi: $10.1093 /$ cercor/bhy225

Vetter, D. E. (2015). Cellular signaling protective against noise-induced hearing loss - A role for novel intrinsic cochlear signaling involving corticotropinreleasing factor? Biochem. Pharmacol. 97, 1-15. doi: 10.1016/j.bcp.2015.06. 011

Viho, E. M. G., Buurstede, J. C., Mahfouz, A., Koorneef, L. L., van Weert, L., Houtman, R., et al. (2019). Corticosteroid Action in the Brain: The Potential of Selective Receptor Modulation. Neuroendocrinology 109, 266-276. doi: 10. $1159 / 000499659$

Wake, H., Watanabe, M., Moorhouse, A. J., Kanematsu, T., Horibe, S., Matsukawa, N., et al. (2007). Early changes in KCC2 phosphorylation in response to neuronal stress result in functional downregulation. J. Neurosci. 27, 1642-1650. doi: 10.1523/JNEUROSCI.3104-06.2007

Wang, F., Hong, B., Han, D. Y., Zhao, L. Y., Sui, Y. N., Liu, Y. Q., et al. (2012). [Changes of gamma-amino butyric acid and electrophysiology inferior colliculus after noise exposure in guinea pig]. Zhonghua Yi Xue Za Zhi 92, 1565-1568.

Wardle, R. A., and Poo, M. M. (2003). Brain-derived neurotrophic factor modulation of GABAergic synapses by postsynaptic regulation of chloride transport. J. Neurosci. 23, 8722-8732. doi: 10.1523/JNEUROSCI.23-25-08722. 2003

Watanabe, M., and Fukuda, A. (2015). Development and regulation of chloride homeostasis in the central nervous system. Front. Cell. Neurosci. 9:371. doi: $10.3389 /$ fncel.2015.00371

Waung, M. W., Pfeiffer, B. E., Nosyreva, E. D., Ronesi, J. A., and Huber, K. M. (2008). Rapid translation of Arc/Arg3.1 selectively mediates mGluR-dependent LTD through persistent increases in AMPAR endocytosis rate. Neuron 59, 84-97. doi: 10.1016/j.neuron.2008.05.014

Wei, H. S., Kang, H., Rasheed, I. D., Zhou, S., Lou, N., Gershteyn, A., et al. (2016). Erythrocytes Are Oxygen-Sensing Regulators of the Cerebral Microcirculation. Neuron 91, 851-862. doi: 10.1016/j.neuron.2016.07.016

Weinberger, N. M. (2015). New perspectives on the auditory cortex: learning and memory. Handbook Clin. Neurol. 129, 117-147. doi: 10.1016/B978-0-44462630-1.00007-X
West, A. E., Pruunsild, P., and Timmusk, T. (2014). Neurotrophins: transcription and translation. Handb. Exp. Pharmacol. 220, 67-100. doi: 10.1007/978-3-64245106-5_4

Wiechers, B., Gestwa, G., Mack, A., Carroll, P., Zenner, H. P., and Knipper, M. (1999). A changing pattern of brain-derived neurotrophic factor expression correlates with the rearrangement of fibers during cochlear development of rats and mice. J. Neurosci. 19, 3033-3042. doi: 10.1523/JNEUROSCI.19-08-03033. 1999

Witkovsky, P. (2004). Dopamine and retinal function. Doc. Ophthalmol. Adv. Ophthalmol. 108, 17-40. doi: 10.1023/b:doop.0000019487.88486.0a

Wu, P. Z., Liberman, L. D., Bennett, K., de Gruttola, V., O’Malley, J. T., and Liberman, M. C. (2019). Primary Neural Degeneration in the Human Cochlea: Evidence for Hidden Hearing Loss in the Aging Ear. Neuroscience 407, 8-20. doi: 10.1016/j.neuroscience.2018.07.053

Xin, W., and Chan, J. R. (2020). Myelin plasticity: sculpting circuits in learning and memory. Nat. Rev. Neurosci. 21, 682-694. doi: 10.1038/s41583-020-00379-8

$\mathrm{Xu}$, H., Kotak, V. C., and Sanes, D. H. (2010). Normal hearing is required for the emergence of long-lasting inhibitory potentiation in cortex. J. Neurosci. 30, 331-341. doi: 10.1523/JNEUROSCI.4554-09.2010

Yates, G. K. (1991). Auditory-nerve spontaneous rates vary predictably with threshold. Hear. Res. 57, 57-62. doi: 10.1016/0378-5955(91)90074-j

Youssofzadeh, V., Vannest, J., and Kadis, D. S. (2018). fMRI connectivity of expressive language in young children and adolescents. Hum. Brain Mapp. 39, 3586-3596. doi: 10.1002/hbm. 24196

Zajac, I. T., and Nettelbeck, T. (2018). Auditory speed tasks as potential candidates for the study of cognitive ageing. Neuropsychol. Dev. Cogn. B Aging Neuropsychol. Cogn. 25, 167-185. doi: 10.1080/13825585.2016.1272671

Zeng, F. G. (2013). An active loudness model suggesting tinnitus as increased central noise and hyperacusis as increased nonlinear gain. Hear. Res. 295, 172-179. doi: 10.1016/j.heares.2012.05.009

Zeng, F. G. (2020). Tinnitus and hyperacusis: Central noise, gain and variance. Curr. Opin. Physiol. 18, 123-129. doi: 10.1016/j.cophys.2020.10.009

Zhu, Y., Qiao, W., Liu, K., Zhong, H., and Yao, H. (2015). Control of response reliability by parvalbumin-expressing interneurons in visual cortex. Nat. Commun. 6:6802. doi: 10.1038/ncomms7802

Zuccotti, A., Kuhn, S., Johnson, S. L., Franz, C., Singer, W., Hecker, D., et al. (2012). Lack of brain-derived neurotrophic factor hampers inner hair cell synapse physiology, but protects against noise-induced hearing loss. J. Neurosci. 32, 8545-8553. doi: 10.1523/JNEUROSCI.1247-12.2012

Zumer, J. M., Brookes, M. J., Stevenson, C. M., Francis, S. T., and Morris, P. G. (2010). Relating BOLD fMRI and neural oscillations through convolution and optimal linear weighting. NeuroImage 49, 1479-1489. doi: 10.1016/j. neuroimage.2009.09.020

Conflict of Interest: The authors declare that the research was conducted in the absence of any commercial or financial relationships that could be construed as a potential conflict of interest.

Publisher's Note: All claims expressed in this article are solely those of the authors and do not necessarily represent those of their affiliated organizations, or those of the publisher, the editors and the reviewers. Any product that may be evaluated in this article, or claim that may be made by its manufacturer, is not guaranteed or endorsed by the publisher.

Copyright (C) 2022 Knipper, Singer, Schwabe, Hagberg, Li Hegner, Rüttiger, Braun and Land. This is an open-access article distributed under the terms of the Creative Commons Attribution License (CC BY). The use, distribution or reproduction in other forums is permitted, provided the original author(s) and the copyright owner(s) are credited and that the original publication in this journal is cited, in accordance with accepted academic practice. No use, distribution or reproduction is permitted which does not comply with these terms. 